\title{
Über die sogenannten Metallverbindungen der Eiweißkörper nach der Theorie der chemischen Gleichgewichte.
}

\author{
Von \\ G. Galeotti. \\ Mit sieben Textfiguren und zwei Tateln. \\ (Der Redaktion zugegangen am 2. Dezember 1903.)
}

Das Studium der sogenannten Metallverbindungen der Eiweißstoffe hat stets eine sehr wichtige Rolle in der Chemie der Eiweißkörper gespielt insofern, als man zu wiederholten Malen versucht und gehofft hat, vermittelst derselben die Größe und Zusammensetzung der Eiweißmoleküle zu bestimmen. Aber die Verschiedenheit und Unbeständigkeit der erhaltenen Resultate gestatten es gewiß nicht, zu behaupten, daß diese Verbindungen der Eiweißkörper mit den Metallsalzen, mit den Halogenen, den Säuren und Basen nach konstanten Koeffizienten vor sich gehen.

Einen Beweis dafür findet man beim Durchlesen der Resultate, welche ich jetzt kurz zusammenfassen werde. Ich beginne mit den Untersuchungen, die sich auf das sogenannte Bindungsvermögen der Eiweißkörper den Säuren und Basen gegenüber beziehen. Diese Untersuchungen stehen ja in gewissem Zusammenhange mit der Frage, welche ich zu behandeln unternommen habe.

Seit Berzelius' Zeiten ist es bekannt, daß viele Eiweißkörper die Eigenschaft besitzen Säuren und Basen teilweise $\mathrm{zu}$ binden, obgleich es sich nicht um eine eigentliche Neutralisierung handelt, da ja ein größerer oder kleinerer Teil der Base oder des Salzes immer frei bleibt, Mulder, Schmidt und Danilewsky suchten die gebundenen Anteile zu bestimmen, und in neuerer Zeit wiederholten andere Autoren diese Bestimmungen mit verschiedenen Methoden.

Sjöqvist(1) berechnete die vom Albumin gebundene $\mathrm{HCl}$, indem er feststellte, wie die elektrische Leitungsfähigkeit einer 
verdünnten Lösung dieser Säure durch die Hinzufügung des Eiweißkörpers beeinflußt wurde. Er nimmt an, daß eine Verbindung stattfände zwischen dem Albumin (das wie eine schwache Base reagieren würde) und der Säure, welche dann die hydrolytische Dissoziation erlitte. Sodann fand er Verschiedenheiten in diesen Verbindungen je nach den Konzentrationen der Substanzen, welche auf einander reagieren sollten.

Cohnheim $\left(^{2}\right)$ bestimmte die von gewissen Eiweißkörpern gebundene HCl-Menge durch Experimente mit Zuckerinversion, welche die Konzentration der H-Ionen ergaben, die nach Hinzufügung des Eiweißkörpers frei geblieben waren. Er fand auch, daß die gebundene Quantität je nach der Konzentration und der Temperatur schwankt.

So z. B. fand er bei einer Protalbumose bei einer Temp. von $40^{\circ}$ in 2,5 \%igen Lösungen bis $4,32 \%$ der $\mathrm{HCl}$

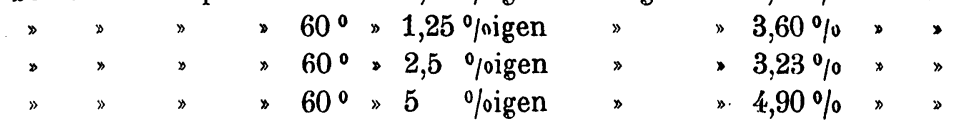

Bugarszky und Liebermann $\left(^{(}\right)$bestimmten die H-Ionen und die $\mathrm{OH}-I$ onen, welche in einer $\mathrm{HCl}$ - oder $\mathrm{NaOH}-\mathrm{Lösung}$ nach Hinzufügung von Albumin freigeblieben waren, indem sie die E. K. diseer Kette

Pt beladen mit $\mathrm{H} \mid$ Säure $\mid$ Base $\mid \mathrm{Pt}$ beladen mit $\mathrm{H}$ abschätzten. Sie fanden, daß das Bindungsvermögen bezüglich der $\mathrm{HCl}$ anfangs proportional mit der Steigerung der Konzentration des Albumins zunimmt, dann langsamer zu steigen fortfährt, was einen Gleichgewichtszustand anzeigt, in welchem die Komponenten der Verbindung HCl-Alb. sich in gewisser Menge regenerieren. Auch hinsichtlich des Bindungsvermögens von $\mathrm{NaOH}$ wurden Werte gefunden, die je nach der Konzentration des Albumins verschieden sind.

Spiro und Pemsel( $\left.{ }^{4}\right)$ behaupteten, man könne das Albumin nicht als eine echte Säure oder als eine echte Base betrachten, und der Neutralisationsprozeß, welcher sich vollzieht, wenn man das Albumin entweder mit einer Base oder einer Säure behandelt, sei nicht als eine einfache Salzbildung zu betrachten. Man erhält eine Verteilung der Säure oder der Base im Albumin

Hoppe-Seyler's Zeitschrift f. physiol. Chemie. XL. 
(gebundener Teil) und im Wasser (freier Teil), welche vollkommen mit so vielen anderen wohl studierten Verteilungsprozessen übereinstimmt.

Cohnheim und Krüger( $\left.{ }^{5}\right)$ und Bohrer( $\left.{ }^{6}\right)$ wandten andere Methoden an, die in der Fällung der Eiweißsäureverbindung vermittelst phosphorwolframsauren Calciums, Pikrinsäure oder $\mathrm{K}_{2} \mathrm{HgJ}_{4}$ und folgender Titrierung des Filtrats bestanden. Auf diese Weise erhielten sie Verbindungsverhältnisse zwischen der Säure und dem Albumin, die von einander selbst um 10-18\% verschieden sind.

Dessen ungeachtet, trotzdem die meisten oben erwähnten Autoren sich für eine echte Verbindung zwischen Säure und Albumin ähnlich derjenigen, welche z. B. zwischen einer Säure und dem Ammoniak eintritt, aussprechen, ist es wohl wahrscheinlicher, daß ein solcher Vorgang als eine Adsorptionserscheinung von seiten des Eiweißkörpers der Säure gegenüber betrachtet werden muß, und daß diese Erscheinung durch die Gesetze der chemischen Gleichgewichte reguliert wird.

Was die Verbindungen der Eiweißkörper mit den Metallen betrifft, so finden wir in der Literatur zahlreiche Untersuchungen, die sehr verschiedene Resultate ergeben haben.

Mir scheint es nutzlos, alle diese Arbeiten hier anzuführen, weil dies in jüngster Zeit mit besonderer Sorgfalt und Ausführlichkeit durch Schulz $\left(^{7}\right)$ geschehen ist; ich beschränke mich deshalb darauf, diejenigen Resultate $\mathrm{zu}$ besprechen, welche in engerem Zusammenhang mit meinen Untersuchungen stehen, ohne dabei auch nur eine chronologische Ordnung innezuhalten.

Zsigmondy $\left({ }^{8}\right)$ hat die Beziehungen zwischen Lösungen von kolloidalem Gold und den Eiweißkörpern studiert und ist $z u$ der Schlußfolgerung gelangt, daß zwischen diesen Substanzen keine echte chemische stöchiometrische Verbindung existiert.

Schulz und Zsigmondy $\left({ }^{9}\right)$ haben in Mischungen von Globulin und kolloidalem Gold ein homogenes rotes Präzipitat erhalten, das sich wieder auflösen kann, und in welchem der Goldgehalt ein sehr schwankender sein konnte. Paal(10) hat ähnliche Untersuchungen ausgeführt mit einigen Metallen im kolloidalen Zustande $(\mathrm{Ag}, \mathrm{Hg}, \mathrm{Au})$ und gewissen eiweißähnlichen 
Substanzen, die er Lysalbinsäure und Protalbinsäure nennt. Er gibt zu, daß diese Säuren mit den erwähnten Metallen mehr oder weniger lösliche Salze bilden, hat jedoch beobachten können, daß man, wenn man solche Zusammensetzungen der Dialyse unterwirft, im äußeren Wasser des Dialysators die organische Säure wiederfindet, während sich keine Spur von dem Metall darin befindet. Schulz bemerkt mit Recht, «wäre das Schwermetall in organischer Bindung in den Säuren vorhanden, so müßte es darin zugleich diffundieren».

Durch eine besondere Methode gelang es Paal $\left({ }^{10}\right)$, den Metallgehalt dieser Präparate bedeutend zu erhöhen, bis er die Zahlen 70-90\% für $\mathrm{Ag}, 40 \%$ für $\mathrm{Hg}$ und $93 \%$ für $\mathrm{Au}$ erreichte.

Die Untersuchungen über die Verbindungen des Albumins mit dem $\mathrm{Pt}$ haben äußerst verschiedenartige Resultate ergeben. Schon Diakonow $\left.{ }^{11}\right)$ und später Fuchs ${ }^{(12}$ ) haben nachgewiesen, daß man mittels einfacher Waschung mit Wasser das $\mathrm{Pt}$ aus dem Präzipitat, das sich gebildet hat, so extrahieren kann, daß der Gehalt aus diesem Metall bis auf 0,8\% sinken kann, während Fuchs aus mehreren Analysen 7,95, 8,77 und 7,6\% erhielt.

Für das Ag erhält man auch von einander sehr abweichende Zahlen. Lieberkühn( $\left.{ }^{13}\right)$ erhielt für Eieralbumin einen Maximalsilbergehalt von 6,1 bis $6,26 \%$, Loew ( $\left.{ }^{4}\right)$, als er mit einem vermittelst der Dialyse gereinigten Eieralbumin experimentierte, bis sein Gehalt an Aschenbestandteilen auf 0,12\% sank, erhielt folgende Resultate.

Eine 5\% oige Albuminlösung ergibt mit einer 1\% \%igen $\mathrm{AgNO}_{3}$ Lösung keinen Niederschlag, mit einer 5-10\% \%igen Lösung dieses Salzes aber einen sehr reichlichen. Aus dem durch $\mathrm{H}_{2} \mathrm{SO}_{4}$ behandelten Albumin erhielt er vermittelst $1 \% \mathrm{AgNO}_{3}$ einen Niederschlag, der, mit Wasser und Alkohol gewaschen, 2,17\% Ag ergab. Nachdem er den Säuregehalt der Flüssigkeit erhöht hatte, erhielt er auch eine Erhöhung des Silbergehalts in dem Niederschlag. Bei Verwendung von 5\% oigen Lösungen von $\mathrm{AgNO}_{3}$ erhielt er folgende Zahlen für den Silbergehalt im Niederschlag: 4,39, 3,91, $4,64 \%$. Daraus ersieht man, daß auch bei Löws Experimenten der Prozentgehalt des Metalls im Niederschlag mit der Steigerung der Konzentration des Salzes in den verwendeten Lösungen zunimmt. 
Si egfrie d(15) fand bei einem seiner Präparate von Eiweiß und Eisen (Carniferrin), daß der Eisengehalt zwischen 35\% und $50 \%$ schwankte, je nach der Konzentration der verwendeten Eisenchloridlösung, und auch für andere Metallsalze erhielt man durch die Analyse der Niederschläge sehr von einander abweichende Zahlen, wie man aus der weiter unten befindlichen Tabelle ersehen kann.

Fano und Enriques( $\left.{ }^{16}\right)$ kommen in einer kürzlich veröffentlichten Arbeit, nachdem sie die Frage gestellt haben, ob wirkliche Verbindungen zwischen Blutserum oder anderen Eiweißkörpern und Eisensalzen oder anderen Elektrolyten zustande kommen, infolge geeigneter Experimente zu der Schlußfolgerung, daß nichts uns gestatte, diese Frage zu bejahen, und daß nichts uns beweise, daß die Eiweißkörper in Wirklichkeit in den organischen Flüssigkeiten mit den Salzen verbunden seien.

Betrachten wir nun die Untersuchungen mit den Kupfersalzen. Harnack(17) ist der Autor, welcher sich am meisten mit diesem Gegenstand beschäftigt hat: er berichtet über die Resultate der Forscher, die ihm vorausgingen. Für das Eieralbumin wurden folgende Werte gefunden

$\begin{array}{llll}\text { Rose } & 1,5-1,69 \% & \mathrm{CuO} \\ \text { Mulder } & 4,44 & \% & \% \\ \text { Mitscherlich } & 2,8--3,3 \% & \% \\ \text { Lieberkühn } & 4,6 & \% & \% \\ \text { Bielitzki } & 4,72-5,19 \% & \% \\ \text { Lassaigne } & 4,95 & \% & \%\end{array}$

die, wie man sieht, sehr wenig mit einander übereinstimmen. Harnack selbst fand in 18 Analysen zwei Reihen von Werten, und die Durchschnittszahlen derselben entsprechen 1,35\% $\mathrm{Cu}$ und $2,64 \% \mathrm{Cu}$. Die erste Verbindung wurde gewonnen, wenn im Eiweiß-, die letztere, wenn in Kupfersalzüberschuß ausgefällt wurde. Außerdem sagt er, und dies ist wichtig und der Erwähnung wert, daß «bei der Herstellung dieser Präparate die Ausfällung niemals nach bestimmten Mengenverhältnissen geschah». Wenn er einer Albuminlösung gerade soviel Kupfersalz hinzufügte, wie es das oben gefundene Verhältnis verlangte, so erhielt er nie einen Niederschlag, sondern zur Erreichung desselben war es nötig, einen Kupfersalzüberschuß hinzuzufügen. 
Mörner $\left.{ }^{18}\right)$ erhielt Kupferalbuminate mit $1,5 \% \mathrm{Cu}$, Chittenden und Whitehouse $\left({ }^{19}\right)$ erhielten ziemlich schwankende Resultate. In den durch einfache Fällung gewonnenen Kupferalbuminaten fanden sie $0,71-1,21 \% \mathrm{Cu}$. Wurde dann der Niederschlag in $\mathrm{NaCO}_{3}$ aufgelöst und wieder durch $\mathrm{HCl}$ gefällt, so stieg der Kupfergehalt auf 1,71\% und nach Wiederholung dieses Vorgangs auf 2,19\%. Brunner erhielt bei einer einzigen Analyse 1,34\%.

Für andere Eiweißkörper haben wir die Untersuchungen von Ritthausen, von Ritthausen und Pott(21) und von Schulz( $\left.{ }^{(21}\right)$. Der erstere beschäftigte sich mit den Kupferverbindungen verschiedener pflanzlicher Eiweißkörper und erhielt folgende Zahlen:

$\begin{array}{lll}\text { Glutencasein aus Weizen } & 16,97 & \% \\ \text { Casein aus Speltkleber } & 14,01-15,23 \% & \text {, } \\ \text { Legumin aus Hafer } & 13,53 & \% \\ \text { Legumin aus Erbsen } & 15,61 & \% \\ \text { Legumin aus Saubohnen } & 13,61-14,10 \% & \text {, } \\ \text { Conglutin aus Lupinen } & 11,18-13,38 \%\end{array}$

Ritthausen und Pott erhielten einen Niederschlag von Casein der Milch, welcher $16-17 \% \mathrm{CuO}$ enthielt.

Schulz fand, daß das Albuminat eines in der Sepiaschulpe vorkommenden Eiweißkörpers bis zu $20 \% \mathrm{CuO}$ zu binden vermochte. Grübler experimentierte mit einem kristallinischen Protein aus den Kürbissamen, und es ergab sich ihm eine Kupferverbindung, die 1,08\% $\mathrm{CuO}$ enthielt.

Um nun zu sehen, wie die Verhältnisse der verschiedenen von einem einzigen Proteid - dem Eieralbumin - gebundenen Metalle variieren, bringe ich umstehend eine Tabelle von Schulz, der ich jedoch auch die sich auf das $\mathrm{Cu}$ beziehenden Zahlen hinzufüge, welche Schulz ausgelassen hat.

Die meisten der S. 498 zitierten Autoren bemühen sich, ihre analytischen Resultate mit den Gesetzen der Äquivalenz in Übereinstimmung zu bringen, wie unter dem gebieterischen Eindruck, daß es nicht möglich sei, irgend eine chemische Erscheinung ohne Anwendung dieser Gesetze zu studieren. In Wirklichkeit scheinen aber solche Bemühungen nicht sehr vom Glück begünstigt $\mathrm{zu}$ werden, und wir finden oft in den oben erwähnten Arbeiten Ausdrücke oder Tatsachen, die völlig mit den die Autoren beherrschenden Gedanken im Widerspruche stehen. 


\begin{tabular}{|c|c|c|c|c|c|c|c|}
\hline & $\mathrm{Cu} \%$ & $\mathrm{Ag} \%$ & Pt $\%$ & $\begin{array}{c}\mathrm{Hg} \\
\%\end{array}$ & $\mathrm{~Pb} \%$ & $\begin{array}{l}\mathrm{Zn} \\
\%\end{array}$ & $\begin{array}{l}\mathrm{Fe} \\
\% \%\end{array}$ \\
\hline Mulder & $\left.3,55^{1}\right)$ & - & - & - & - & - & - \\
\hline Mitscherlich & $\left.2,24-2,64^{1}\right)$ & - & - & - & - & - & - \\
\hline Bielitzki. . & $\left.3,77-4,15^{\prime}\right)$ & -- & - & - & - & - & - \\
\hline Lassaigne & $\left.3.96^{1}\right)$ & - & - &.- & - & - & - \\
\hline Mörner . & 1,2 & - & - & - & - & $1-$ & - \\
\hline Harnack. . & $1,35-2,64$ & - & - & - & - & $1-1$ & - \\
\hline Rose & $\left.1,20-1,35^{1}\right)$ & - & -- & - & - & 2,16 & 1,99 \\
\hline Lieberkühn & $\left.3,68^{1}\right)$ & $6,1 \quad 6,26$ & - & - & $\left.2^{2}\right)$ & 3,7 & - \\
\hline Schwarzenbach & - & - & 5,7 & -1 & - & -1 & - \\
\hline Diakonow . . & - & - & $0,8-6,3$ & - & - & -1 & - \\
\hline Fuchs . . . . & - & 3,3 & $\begin{array}{c}0,8-5,9 \\
8,1\end{array}$ & -1 & - & $1-$ & - \\
\hline Commaille. . & - & - & $9-10,8,02$ & - & - & -1 & - \\
\hline Loew . . . & - & $\begin{array}{c}2,17,2,28 \\
4,31 \\
4,39,4,64\end{array}$ & - & - & - & - & - \\
\hline $\begin{array}{l}\text { Chittenden u. } \\
\text { Whitehouse }\end{array}$ & $\begin{array}{ll}0,7, & 1,21 \\
1,71, & 2,19\end{array}$ & $\begin{array}{l}3,91,4,09 \\
4,86,5,72\end{array}$ & - & 2,89 & $\mid \begin{array}{l}\left.2,2-2,8^{3}\right) \\
\left.2,4-32,1^{4}\right)\end{array}$ & 0,91 & 0,95 \\
\hline Brunner. . . & 1,34 & - & - & 7,5 & - & - & 1,06 \\
\hline
\end{tabular}

Harnack z. B., der zuerst versichert, es sei ihm gelungen, die Existenz von zwei verschiedenen, aber typischen Verbindungskoefficienten zwischen Albumin und $\mathrm{Cu}$ nachzuweisen, welche sich wie $1: 2$ verhielten, muß später, wie wir gesehen haben, bekennen, daß, wenn man Albumin und Kupfersalz in dem erwähnten Verhältnis miteinander vermischt, sich durchaus kein Niederschlag bildet, und er gibt auch $\mathrm{zu}$, daß die Verbindung des Eiweißkörpers mit dem $\mathrm{Cu}$ so labil sei, daß die einfache, aber lange fortgesetzte Waschung mit Wasser genüge, um das ganze Metall fortzuschwemmen. Paal versichert uns, es existierten zwei ganz bestimmte Salzverbindungen zwischen den Schwermetallen und den von ihm dargestellten Proteinderivaten, während er nachher, wie gesagt wurde, findet, daß. in der Dialyse die Proteinsäureradikale sich von dem Metall-

1) Berechnet aus den auf Seite 496 dargestellten Werten von $\mathrm{CuO}$.

2) Keine konstanten Werte.

3) Mit basischem Bleiacetat gefällt.

4) Mit neutralem Bleiacetat gefällt. 
salze trennten, so daß erstere durch die Membrane hindurchgehen, letzteres hinter derselben zurückbleibt. Außerdem gelingt es ihm selbst, Mischungen zu präparieren, welche mehr als 70\% Ag oder 93\% Au enthalten, Zahlen, welche diejenigen irgend einer möglichen Verbindung übersteigen. Wenn ferner die silberhaltigen Albuminate (des Eiereiweißes) den beiden kupferhaltigen Albuminaten Harnacks entsprächen, so müßten sich Albuminate mit nur 2,2\% und $4,4 \%$ Ag finden. In der Tat finden sich Zahlen, welche diesen nahe kommen, in den Analysen von Loew, aber eingeschaltet in einer Reihe von anderen Werten, die fast mit Stetigkeit variieren, wie folgt:

2,17-2,28\% (Loew), 3,3\% (Fuchs), 3,91-4,09\% Chittenden-Whitehouse), $4,39 \%-4,64 \%$ (Loew), $4,86-5,72 \%$ (Chittenden-Whitehouse), 6,1-6,26\% (Lieberkühn).

In ähnlicher Weise berechnet Harn a ck, man müsse, wenn man seine kupferhaltigen Albuminate zur Grundlage nehme, platinhaltige Albuminate des Eiereiweißes finden, in welchen zwei Atome Pt für jedes Molekül vorhanden wären, d. h. man müßte in diesen $7,9 \% \mathrm{Pt}$ erhalten.

Nun hat allerdings $\mathrm{Fuchs}$ diesen nahekommende Werte gefunden, aber sie sind in der folgenden Reihe eingeschaltet:

$0.8 \%$ (Diakonow und Fuchs), 5,7\% (Schwarzenbach), 6,3\% (Diakonow), 7,6-8,770\% (Fuchs), 9,10\% (Commaille), und etwas Ähnliches läßt sich bezüglich anderer Metalle $(\mathrm{Hg}, \mathrm{Pb}, \mathrm{Zn}, \mathrm{Fe})$ widerholen, wie sich aus der oben angeführten Tabelle ergibt.

Wenn man endlich eine echte Verbindung zwischen den Metallen und den Eiweißmolekülen annähme, wie könnte man dann den sehr großen Unterschied zwischen der von Eiweißkörpern verschiedener Natur gebundenen $\mathrm{Cu}$-Menge erklären, wie sich aus den auf S. 497 angeführten Zahlen ergibt? Man müßte annehmen, daß das Molekulargewicht der Eiweißkörper in sehr großen Grenzen schwanken könnte, oder daß, während z. B. ein Molekül Eiereiweiß imstande wäre, 1 oder 2 Atome $\mathrm{Cu}$ zu binden, ein Molekül Pflanzeneiweiß imstande wäre, 15 oder $20 \mathrm{zu}$ binden, was doch höchst unwahrscheinlich ist. 
Schon aus dieser kritischen Prüfung der in bezug auf diese Frage angestellten Untersuchungen erhellt mithin, daß bei der Bildung der Metallalbuminate das Gesetz der Äquivalenz sich nicht bewahrheitet, und man wird nachher aus dem Folgenden ersehen, wie sehr meine Experimente dieser Behauptung zur Stütze dienen. Von welcher Natur sind nun diese sogenannten $\left.{ }^{1}\right)$ Verbindungen?

Diese Frage hat beim gegenwärtigen Stande der Chemie keine fundamentale Bedeutung.

Heutzutage wird allgemein anerkannt, daß zwischen den physikalischen Gemischen und den echten chemischen Verbindungen in bestimmten Verhältnissen verschiedene Zustände mehr oder weniger inniger Bindung zwischen Substanzen von verschiedener Beschaffenheit existieren, und daß wir über die Natur dieser Vorgänge ${ }^{2}$ ) (die mit den Namen Adhäsion, Adsorption, Verteilungsfähigkeit, Bildung fester Lösungen usw. bezeichnet wurden) ebensowenig wissen, wie über die innere Zusammensetzung der wahren Verbindungen.

Für den Chemiker ist es aber von geringem Interesse, ob der Vorgang, welcher in dem einen oder dem anderen Falle sich vollzieht, mit dem einen oder dem anderen Namen bezeichnet werden muß; wohl aber ist es von Wichtigkeit, das

1) Schulz macht in seiner schönen Monographie «die Größe des Eiweißmoleküls» folgende Bemerkungen:

«Ich habe den Ausdruck «Verbindung » z. B. Kupfereiweißverbindung, mehrfach gebraucht. Ich verwende diesen Ausdruch der Kürze halber da, wo Eiweiß mit einem anderen Stoffe in Reaktion tritt, ohne damit anzeigen zu wollen, daß die betreffenden Reaktionsprodukte für chemische Verbindungen im Sinne der Valenztheorie zu halten sind. Eine Hauptaufgabe dieser Abhandlung war es gerade, daß gezeigt wird, daß bisher keine zwingenden Gründe vorliegen, um z. B. bei den Metallalbuminaten, oder später bei den Halogenalbuminaten, Verbindungen der Eiweißstoffe nach stöchiometrischen Gesetzen annehmen zu müssen». Auch ich stimme mit diesem Autor überein, eine solche Einschränkung zu-machen, und insofern es bequem ist, wenn auch in anderer Bedeutung, diese Ausdrücke beizubehalten, namentlich den Ausdruck Albuminat (z. B. Silberalbuminat, Kupferalbuminat), die ich weiter verwenden werde, um die Niederschläge des Albumins mit den Metallsalzen zu bezeichnen.

2) Cfr. in dieser Hinsicht: Bemmelen, Zeitschr. f. physik. Chemie, Bd. XVIII, S. 321 und Nernst, Theoretische Chemie, 2. Auflage, S. 32. 
Gesetz zu bestimmen, welches die Bildung der Verbindung bestimmt; dieses Gesetz wird im Falle der Verbindungen in bestimmten Verhältnissen einfach durch konstante Koeffizienten, in den anderen Fällen durch mehr oder weniger komplizierte Funktionen der Konzentrationen, der Temperatur und des Druckes dargestellt werden.

Folglich besteht das Problem, welches am meisten des Studiums würdig ist, darin, solche Funktionen vermittelst der Bestimmung der Gleichgewichtszustände in den Systemen, mit deren Untersuchung man sich beschäftigt, kennen zu lernen.

Einleitende Untersuchungen.

Mischt man eine Lösung von Albumin (Eieralbumin oder Serumalbumin) mit einer Lösung von $\mathrm{CuSO}_{4}$ oder $\mathrm{AgNO}_{3}$ in verschiedenen Verhältnissen, so kann man Erscheinungen der Ausfällung sowie der Wiederauflösung des Niederschlags ${ }^{1}$ ) beobachten. Bringt man in ein Gläschen wenige Zehntel Kubikcentimeter einer $\mathrm{n} / 10$-Lösung von $\mathrm{CuSO}_{4}$ und fügt dann vermittelst einer Bürette Tropfen um Tropfen einer ca. 3\% igen Albuminlösung hinzu, so sieht man zuerst, wie sich ein dichter Niederschlag bildet, der dann bei Hinzufügung einer größeren Menge von Albumin sich wieder auflöst, und so erhält man endlich eine homogene Lösung. Fügt man noch $\mathrm{CuSO}_{4}$ hinzu, so erhält man einen neuen Niederschlag, den man alsdann wiederum durch einen Überschuß von Albumin wieder auflösen kann.

Alsdann erhält man für eine gewisse Reihe von Beziehungen zwischen der Menge des Albumins und derjenigen des $\mathrm{CuSO}_{4}$ stets einen reichlichen Niederschlag. Letzterer fällt langsam und hinterläßt eine Flüssigkeit, die durchaus nicht klar ist, wenn man relativ kleine Mengen $\mathrm{CuSO}_{4}$ verwendet

1) In dieser Hinsicht erwähne ich folgende bibliographische Notizen: Rose ( $\left.{ }^{22}\right)$ fand, daß ein frisch hergestelltes Kupferalbuminat sich in einem Überschuß von Albumin löst, und Mitscherlich versichert, es löse sich auch wieder auf in einem Überschuß von Salz. Neebe $\left({ }^{22}\right)$ konstatierte, daß der durch Einwirkung des essigsauren $\mathrm{Cu}$ auf das Albumin erhaltene Niederschlag sich löst, wenn man die Konzentration des Acetats erhöht. Auch Harnack fand, daß ein Überschuß an Albumin oder $\mathrm{CuSO}_{4}$ genügt, um den Niederschlag, der sich zuerst gebildet halte, wieder aufzulösen. 
hat; er fällt dagegen sogleich und hinterläßt eine sehr klare Flüssigkeit, wenn die Mischung mit größeren Mengen von Kupferlösung gemacht wurde.

In allen beiden Fällen jedoch enthält die durch Filtrierung geschiedene Flüssigkeit noch reichlich Albumin, wie man beim Kochen der Flüssigkeit sehen kann, weil sie alsdann trübe wird und hierauf einen reichlichen flockigen Niederschlag gibt; zuweilen gerinnt sie auch in kompakter Weise.

In den Mischungen von Silbernitrat und Albumin sind diese Erscheinungen noch deutlicher.

Tröpfelt man eine Albuminlösung in einige Kubikcentimeter einer $1 \%$ igen Lösung von $\mathrm{AgNO}_{3}$, so sieht man zuerst, wie sich ein flockiger Niederschlag bildet, der sich hierauf durch einen Überschuß von Albumin wieder auflöst. Läßt man einige Tropfen der Lösung des Silbers in die Albuminlösung fallen, so sieht man, daß sich kein Niederschlag bildet, bis die hineingezogene Quantität der Silberlösung einen gewissen Wert erreicht. Ist aber dieser Wert erreicht, den man mit einiger Aufmerksamkeit leicht bestimmen kann, so beginnt sich der Niederschlag zu bilden und nimmt zu mit jedem neuen Tropfen der Silberlösung.

Fügt man dann wieder Albumin hinzu, so löst sich der Niederschlag wieder.

Sehen wir nun, was geschieht, wenn dem Albumin gegenüber ein Überschuß an Metallsalz vorhanden ist. Gießt man in einige Kubikcentimeter einer konzentrierten Lösung von $\mathrm{CuSO}_{4}$ Tropfen um Tropfen eine Albuminlösung, so sieht man, wie sich ein Niederschlag bildet an der Stelle, wo der Albumintropfen in die Flüssigkeit fällt; schüttelt man aber das Glas, so verschwindet der Niederschlag. Die Lösung bleibt lange Zeit hindurch vollständig klar, aber ihre Farbe ändert sich und nähert sich mehr der grünen: bei fortwährender Hinzutügung von Albumin sieht man, wie der Niederschlag sich mit immer größerer Schwierigkeit löst und endlich bleibt.

Gießt man hingegen Tropfen um Tropfen einer konzentrierten Lösung von $\mathrm{CuSO}_{4}$ in eine Albuminlösung, so sieht man, wie sich zuerst ein dichter Niederschlag bildet, der dann durch Hinzufügung von $\mathrm{CuSO}_{4}$ sich allmählich löst, und man 
erhält endlich eine sehr klare smaragdgrüne Lösung, welche Albumin in großen Mengen enthält. Die Hinzufügung von Wasser verursacht in dieser Lösung die Bildung eines flockigen Niederschlages. ${ }^{1}$ ) Wie ich weiter unten darlegen werde, habe ich diese Eigenschaft benutzt, um konzentrierte Albuminlösungen in gesättigten Lösungen von $\mathrm{CuSO}_{4}$ zu erhalten. Zu diesem Zwecke genügt es, auf einem Filter den aus einer beliebigen Mischung von Albumin und $\mathrm{CuSO}_{4}$ erhaltenen Niederschlag zu sammeln und ihn wieder aufzulösen, was mit der größten Leichtigkeit in einer übersättigten Lösung von $\mathrm{CuSO}_{4}$ geschieht. Die Flüssigkeit, welche man erhält, ist vollkommen klar, grün, hat eine besondere Refraktion und läßt sich, was einigermaßen überrascht, gut und sehr schnell filtrieren. Beim Erwärmen gibt sie einen äußerst reichlichen Niederschlag von geronnenem Albumin. Durch einfache Hinzufügung von Wasser erhält man auch ein Kupferalbuminat.

Diese einleitenden Untersuchungen beweisen, daß die Niederschlagung des Albumins durch eines dieser Metallsalze eine reversible Erscheinung ist, und sie geben schon die Umrisse der wichtigsten Kennzeichen des Gleichgewichts bei diesen Systemen. Bezeichnen wir mit L die flüssige Phase, d. h. die Lösung, und mit $\mathrm{P}$ die feste Phase, d. h. den Niederschlag, so ist die Formel des Gleichgewichtes

$$
\mathrm{L}+\mathrm{P} \rightleftarrows \mathrm{L}
$$

und, wie wir gesehen haben, genügt die Hinzufügung eines der drei Bestandteile in genügender Menge zu einem schon im Gleichgewicht befindlichen System, um dieses gegen das rechte oder gegen das linke Glied der vorausgehenden Formel zu verschieben; dasselbe erhält man durch Hinwegnahme eines der Bestandteile oder, was dasselbe ist, wenn man die Verhältnisse der beiden anderen verstärkt.

Außerdem beweisen diese einleitenden Untersuchungen, daß bei der Fällung keiner der beiden Bestandteile erschöpft werden kann (wie schon Harnack fand), sondern daß in der

1) Alle diese Erscheinungen der Niederschlagbildung und Wiederauflösung ändern sich sehr durch die Anwesenheit auch sehr kleiner Mengen einer Säure oder Base. 
Lösung Teile von beiden zurüçkbleiben. Dies führte $\mathrm{zu}$ der Annahme, das Metallsalz habe, wenn es aus der Lösung entfernt wird, die Tendenz, auch aus dem Niederschlag zu verschwinden, und dieses Ergebnis zeigte sich mir in der Tat infolge eines sehr einfachen Experimentes.

Ich sammelte eine reichliche Menge von Silberalbuminat, das aus der einfachen Mischung einer Lösung von Eiereiweiß mit $\mathrm{AgNO}_{3}$ gebildet war, brachte es in ein großes Glas Wasser und schüttelte eine Zeitlang, um die Flocken des Niederschlags gut zu waschen - hierauf filtrierte ich - dem Filter entnahm ich einen kleinen Teil des Niederschlags, um ihn sogleich der Analyse zu unterziehen: der Rest wurde 4 Tage lang einer fortwährenden Waschung mit fließendem destillierten Wasser unterworfen; in gewissen Zeitabständen entnahm ich neue Teile des Niederschlages und führte die Analyse derselben aus.

Die Resultate dieses Experimentes sind in der folgenden Tabelle enthalten:

\begin{tabular}{l|c|c|c|c}
\hline & $\begin{array}{c}\text { Gewicht } \\
\text { des trockenen } \\
\text { Niederschlages }\end{array}$ & $\begin{array}{c}\text { Ge- } \\
\text { fundenes } \\
\mathrm{AgCl}\end{array}$ & $\mathrm{Ag}$ & $\begin{array}{c}\mathrm{Ag} \% \\
\text { des trockenen } \\
\text { Niederschlages }\end{array}$ \\
\hline $\begin{array}{l}\text { 1. Teil sogleich nach der } \\
\text { Waschung analysiert }\end{array}$ & 0,2616 & 0,0718 & 0,0563 & 21,52 \\
$\begin{array}{l}\text { 2. Teil, nach 24stündiger } \\
\text { Waschung analysiert }\end{array}$ & 0,2488 & 0,0584 & 0,0439 & 17,67 \\
$\begin{array}{c}\text { 3. Teil, nach 48stiindiger } \\
\text { Waschung analysiert }\end{array}$ & 0,2614 & 0,0576 & 0,04333 & 16,58 \\
$\begin{array}{l}\text { 4. Teil nach 4tägiger } \\
\text { Waschung analysiert }\end{array}$ & 0,1572 & 0,0313 & 0,0284 & 14,95
\end{tabular}

Man sieht sogleich, daß die Menge des durch das Albumin gebundenen Metalls allmählich im Verhältnis zur Zunahme der Zeit der Waschungen abnimmt; dies ist auch ein weiterer Beweis dafür, daß es sich bei diesen Systemen nicht um bestimmte Verbindungen handelt.

Ein dritter Punkt, den ich auch aufzuklären wünschte, als ich das Studium der Gleichgewichtszustände bei diesen Systemen begann, war folgender: ich wollte sehen, wie sich die Metallsalze mit dem Albumin bei der Bildung des Niederschlages vereinigen. 
In dieser Hinsicht behauptete Mitscherlich, nachdem er eine Reihe von Bestimmungen des Gehaltes der gewöhnlichen Kupferalbuminate an $\mathrm{Cu}$ und $\mathrm{H}_{2} \mathrm{SO}_{4}$ ausgeführt hatte, das ganze Molekül $\mathrm{CuSO}_{4}$ vereinige sich mit dem Albumin; diese Behauptung wurde aber dann bestritten von Rose, Lieberkühn und Harnack, die versicherten, bei der Bildung des Kupferalbuminates gehe eine Spaltung des Kupfersulfats in $\mathrm{CuO}$ und $\mathrm{H}_{2} \mathrm{SO}_{4}$ vor sich.

Ich habe jedoch Mitscherlichs Experimente wiederholen wollen, indem ich gleichzeitig das $\mathrm{CuO}$ und die $\mathrm{H}_{2} \mathrm{SO}_{4}$ (gut gewaschener) Niederschläge analysirte, die ich mit Eieralbumin erhalten hatte, dessen Gehalt an $\mathrm{S}$ ich vorher bestimmt hatte. In beiden Fällen behandelte ich mit $\mathrm{HNO}_{3}$ und $\mathrm{KNO}_{3}$ (im Gegensatz zu Rose, der einfach einäscherte), um den ganzen $S$ in der Form von Schwefelsäure zu erhalten. Wenn dies $\mathrm{CuSO}_{4}$ als solches im Niederschlag enthalten war, so mußte die gesamte gefundene $\mathrm{H}_{2} \mathrm{SO}_{4}$ gleich sein der aus dem erhaltenen $\mathrm{CuO}$ berechneten Menge $\mathrm{H}_{2} \mathrm{SO}_{4}$ plus der Menge der $\mathrm{H}_{2} \mathrm{SO}_{4}$, die aus dem im Albumin enthaltenen $\mathrm{S}$ berechnet worden war.

Ich muß zugeben, daß es mir bei verschiedenen Analysen nicht gelungen ist, eine genügende Übereinstimmung der Resultate in diesem Sinne zu erreichen (und halte es deshalb nicht für nötig, hier die numerischen Daten dieser Analysen anzugeben), obgleich jedoch in jedem Falle sich mir eine bedeutend größere Menge $\mathrm{H}_{2} \mathrm{SO}_{4}$ ergab als die, welche der $\mathrm{S}$ des Albumins allein mir hätte ergeben können.

Deshalb kann ich die Frage nicht mit Sicherheit in dem von Mitscherlich ausgesprochenen Sinne entscheiden, glaube jedoch nicht $\mathrm{zu}$ irren, wenn ich, trotz der entgegengesetzten Resultate der oben erwänten Autoren, zu seiner Ansicht hinneige. Diese doppelten Analysen, welche auf den ersten Blick leicht erscheinen, bieten indessen große Schwierigkeiten dar und verlangen sehr viel Zeit sowie eine außerordentliche Genauigkeit; deshalb mußte ich, obwohl die endgültige Lösung dieses Problems mich im höchsten Grade interessierte, dasselbe aus verschiedenen Gründen beiseitelegen, behielt mir jedoch vor, es von neuem ausführlicher und mit größerer Sicherheit zu 
behandeln, wenn ich auch andere mit anderen Salzen erhaltene Metallalbuminate der Untersuchung unterzöge.

Es könnte vielleicht scheinen, als ob von der Lösung dieses Problems in unumgänglich notwendiger Weise die ganze Behandlung meines Gegenstandes abhinge, aber dies ist in Wirklichkeit nicht der Fall, insofern es für meine Resultate keinen wesentlichen Unterschied bedeutet, ob das Kupfer sich mit dem Albumin vereinigt findet in der Form eines Oxyds oder eines Sulfats. Die von mir studierten Erscheinungen würden sich auf einfachere Weise erklären lassen, wenn ganze Moleküle $\mathrm{CuSO}_{4}$ durch das Albumin gebunden würden; aber andererseits könnten wir die zweite Möglichkeit erklären, wenn wir uns erinnern, daß in der Lösung von $\mathrm{CuSO}_{4}$ eine gewisse Anzahl von Molekülen des Salzes hydrolytisch in $\mathrm{CuO}$ und $\mathrm{H}_{2} \mathrm{SO}_{4}$ dissoziiert sind, und daß das Albumin zuerst gerade diese Teile $\mathrm{CuO}$ binden könnte; alsdann würde sich das Gleichgewicht der hydrolytischen Dissoziation verschieben, und neue Moleküle des Kupfersalzes würden sich abtrennen und so weiter, bis das Gleichgewicht zwischen dem Niederschlag und der Lösung erreicht wäre.

So können auch die Resultate von Linden und Pichon( $\left.{ }^{23}\right)$, Whitney und Ober ( ${ }^{24}$ ) erklärt werden, die ebenfalls sich auf die Ausfällung gewisser Cilloide durch Elektrolyten bezogen: sie fanden, daß vom Colloid kleine Mengen des Metallhydroxyds adsorbiert werden, da die ursprünglich neutrale Lösung des fällenden Salzes nach der Fällung schwach sauer reagierte, während in den Flocken des Niederschlages das Metalloxyd nachgewiesen werden konnte.

Aber, wie ich schon angedeutet habe, mögen sich die Dinge so oder anders verhalten, daran ändern die Resultate, welche ich später anführen werde, im wesentlichen nichts. Einstweilen lege ich Gewicht auf die oben erwähnten Untersuchungen, welche, wenn sie auch nicht entscheidend sind, doch die Ansicht Mitscherlichs unterstützen, und habe alle meine analytischen Resultate berechnet, als ob das $\mathrm{Cu}$ und das $\mathrm{Ag}$ in den Niederschlägen unter der Form eines Sulfats resp. Nitrats enthalten wären. Aber wenn sie statt dessen als unter der Form von Oxyden enthalten betrachtet 
Über d. sog. Metallverbindungen d. Eiweißkörper nach d. Theorie etc. 507

werden müßten, so könnte man leicht vermittelst einer einfachen Umrechnung die neuen centesimalen Werte der Verbindungen erhalten und durch sie die Kurven wiederherstellen, welche dann ihre Form wohl nicht wesentlich ändern würden.

Nachdem ich so konstatiert hatte, daß die Fällung eines Eiweißkörpers durch das Salz eines Schwermetalles ein reversibler Vorgang ist, und nachdem die oben angeführten Literaturstudien in mir den Gedanken hervorgerufen hatten, daß die Zusammensetzung des Niederschlages von der Konzentration des $\mathrm{CuSO}_{4}$ und des Albumins in der rückständigen Lösung abhinge, und daß es sich mithin um das Gleichgewicht eines zweiphasischen Systemes mit drei Bestandteilen handelte, wollte ich es unternehmen, beim Studium dieser Systeme die Methoden zur Anwendung zu bringen, welche die chemische Mechanik uns lehrt.

\section{Theoretisches.}

Gemäß den allgemeinen Grundsätzen der Thermodynamik läßt sich die Bestimmung der Gleichgewichtsbedingungen eines Systems von mehreren Phasen auf die Kenntnis einer charakteristischen Funktion zurückführen, welche das thermodynamische Potential genannt wird. Während man aber bekanntlich die Existenz dieser Funktion für jedes beliebige System nachweisen und ebenfalls beweisen kann, daß sie eine stetige und mit besonderen Eigenschaften ausgestattete ist, kann man in der Mehrzahl der Fälle ihren analytischen Ausdruck nicht bestimmen, so daß die Behandlung der Probleme der chemischen Gleichgewichte mit den von der mathematischen Analyse gelieferten Methoden bis jetzt keine großen Fortschritte gemacht hat. Aber Gibbs hat einen Weg angegeben, bei dessen Verfolgung schon sehr befriedigende Resultate erreicht wurden, besonders durch Bakhuis-Roozeboom( $\left.{ }^{26}\right)$, Rijn van Alkemade $\left({ }^{27}\right)$, Schreinemakers(28) u. a. - Diese Autoren haben gezeigt, wie man geometrisch die thermodynamischen Eigenschaften eines mehrphasigen Systems so darstellen kann, daß die Gleichgewichtszustände der Phasen durch graphische Methoden 
vollkommen bestimmt werden. Andererseits hat die rein geometrische Behandlung der bei der Darstellung dieser Erscheinungen verwendeten Elemente zu Erweiterungen der Theorie geführt, zu neuen anfangs nicht erwarteten Resultaten, welche dann durch die Experimente bestätigt wurden.

Und so existiert jetzt (besonders vertreten durch Schreinemakers) eine vollständige allgemeine Theorie bezüglich der Gleichgewichte der Systeme von 2 oder 3 Bestandteilen; ich aber werde hier nur die grundlegenden Prinzipien der Methode und ihre Anwendungen auf einige besondere Fälle eines Systems mit drei Komponenten in zwei oder drei Phasen erwähnen.

Nach Gibbs können die Zusammensetzungen eines Systems von drei Komponenten in der Ebene dargestellt werden durch

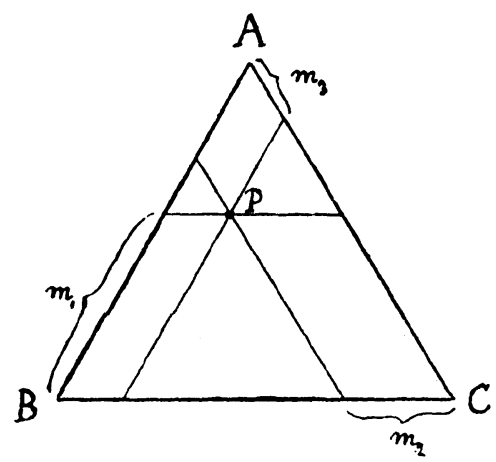

Fig. 1. die Punkte des Flächeninhalts eines gleichseitigen Dreiecks, dessen Seiten gleich 100 sind. Es seien A, B, C (Fig. 1) die 3 Bestandteile. Das durch den Bestandteil $A$ in der Quantität $\mathrm{m}_{1}$, den Bestandteil $\mathrm{B}$ in der Quantität $\mathrm{m}_{2}$ und den Bestandteil $\mathrm{C}$ in der Quantität $\mathrm{m}_{3}$ gebildete System (diese drei Quantitäten sind durch die Gleichung $\mathrm{m}_{1}+\mathrm{m}_{2}+\mathrm{m}_{3}=$ 100 verbunden) wird durch den Punkt $\mathrm{P}$ dargestellt.

Der Scheitelpunkt A stellt die Phase dar, welche allein durch den Bestandteil A gebildet wird, der Scheitelpunkt B die durch den Bestandteil $B$ allein gebildete Phase, der Scheitelpunkt $\mathrm{C}$ den Bestandteil $\mathrm{C}$ allein. Die Punkte der Seite AB die durch $\mathrm{A}$ und $\mathrm{B}$ in allen Verhältnissen zusammengesetzten Phasen, die Punkte der Seite AC alle Phasen mit A und C und die Punkte der Seite BC die Phasen mit B und $\mathrm{C}$.

Eine kontinuierliche Kurve im Flächeninhalt des Dreiecks wird ein Gesetz bezeichnen, das für alle Phasen gilt, welche durch die Punkte der Kurve selbst dargestellt werden, und wird 
die Bezeichnung Isotherme erhalten, weil durch diese Methode die Gleichgewichte bei einer einzigen konstanten Temperatur dargestellt werden. Man kann jedoch die Isothermen für verschiedene Temperaturen entwerfen: alsdann erhält man ebensoviele Dreiecke, welche, übereinander gestellt, ein Prisma bilden (die Achse des Prismas ist die Achse der Temper.), das in seinem Innern eine Oberfläche enthält, welche aus der Übereinanderstellung der verschiedenen Isothermen besteht. Im gegenwärtigen Falle aber werde ich mich auf die Behandlung einer einzigen Isotherme beschränken, weshalb es keinen Zweck hat, daß ich dazu übergehe, den umsomehr komplizierten Fall dieser geometrischen Darstellungen im Raume theoretisch zu betrachten. Errichten wir jetzt eine Senkrechte durch jeden Punkt des Dreiecks ABG und geben wir einer jeden von diesen Senkrechten eine Länge gleich dem thermodynamischen Potential, welcher zu dem System gehört, das durch den Punkt dargestellt wird, über welchem die Senkrechte errichtet worden ist.

Die oberen Endpunkte dieser Senkrechten bilden eine Fläche, welche den Namen Potentialfläche oder $\tau$-Fläche führt.

Rijn van Alkemade hat nachgewiesen, daß, falls stabile Phasen vorhanden sind, diese Fläche allgemein gegen die Ebene des Dreiecks hin konvex ist, und daß die senkrecht auf den Seiten des Dreiecks errichteten Ebenen Berührungsebenen derselben sind. Auf dieser Fläche sind oft Falten und zuweilen Nabel vorhanden, deren Projektionen auf die Ebene des Dreiecks einige von den oben erwähnten Isothermen oder singulären Punkten bilden, die Systeme oder mit besonderen Eigenschaften aúsgestattete Phasen darstellen.

Fig. 2 gibt eine Vorstellung von diesen Potentialflächen. Die Geraden $\mathrm{A} \tau_{1}$,

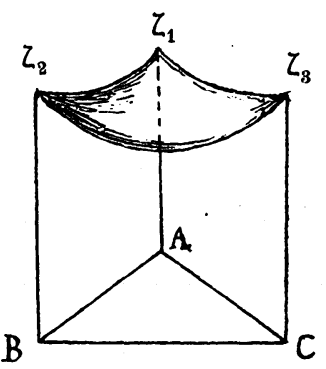

Fig. 2. $\mathrm{B}_{2}$ und $\mathrm{C} \boldsymbol{z}_{3}$ stellen beziehungsweise die Potentialwerte der Einheiten der Masse der Phasen dar, die aus einem einzigen Komponenten $\mathrm{A}$ oder $\mathrm{B}$ oder $\mathrm{C}$ bestehen, die Kurven $\tau_{1} \tau_{2}, \tau_{1} \tau_{3}$ und $\tau_{2} \tau_{3}$ die geometrischen Orte von den Potentialen der binären Phasen $\mathrm{A}+\mathrm{B}, \mathrm{A}+\mathrm{C}$ und $\mathrm{B}+\mathrm{C}$.

Hoppe-Seyler's Zeitschrift f. physiol. Chemie. XL. 
Betrachten wir nun ein nur aus einer festen Phase, der Substanz B, und aus einer Lösung zusammengesetztes System, welche die drei Komponenten A (Lösungsmittel), B und C enthält, und suchen wir, welches die Isotherme ist, die alle möglichen Gleichgewichtszustände dieses Systems darstellt.

$\mathrm{Zu}$ diesem $\mathrm{Zwecke}$ erinnern wir uns zunächst, daß, wenn 2 Punkte der Z-Fläche zwei im Gleichgewicht unter einander stabilen Phasen entsprechen, diese beiden Punkte derselben die Fläche berührenden Ebene angehören und alle beide Berührungspunkte sind. (Cfr. Rijn van Alkemade, Zeitschr. f. physyk. Chemie Bd. XI, p. 307). Außerdem stellt die Projektion auf die Ebene des Dreiecks der Geraden, welche sie vereinigt, mit ihren Punkten labile Systeme dar, die das Streben haben, sich in den beiden Phasen im Gleichgewicht zu spalten.

Hierauf lassen wir durch den Punkt $\zeta_{1}$, der das Potential der Einheit der Masse von A darstellt, alle die unendlichen Ebenen hindurchgehen, welche Tangenten der Z-Fläche sind; sie hüllen einen Kegel ein, und die Berührungslinie dieses Kegels mit der Fläche selbst, auf die Ebene des Dreiecks projiziert, stellt die gesuchte Isotherme dar.

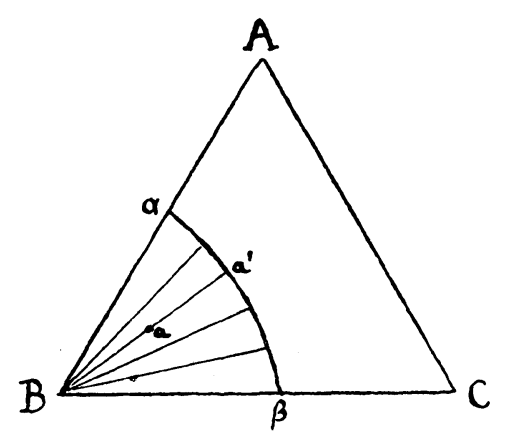

Fig. 3.

In der Fig. 3 ist diese Isotherme die Kurve $\alpha \beta$; sie teilt den Flächeninhalt des Dreiecks in zwei Felder; die im FeldeB $\alpha \beta$ gelegenen Punkte stellen Systeme dar, welche mit dem Eintreten des Gleichgewichts sich spalten in die Komponente $\mathrm{B}$ und in eine der stabilen durch die Punkte der Kurve $\alpha \beta$ dargestellten

Lösungen: dieses Feld kann man daher ein $z$ weiphasisches nennen. Dadurch ist das Problem des Gleichgewichts in diesem Falle einfacher, und für die der Isotherme $\alpha \beta$ entsprechende Temperatur vollständig gelöst. In der Tat, wenn irgend ein beliebiges System gegeben ist, das aus $\mathrm{A}+\mathrm{B}+\mathrm{C}$ in bestimmten Mengen zusammengesetzt ist, so kann man, wenn man den 
Punkt sucht, der es im obenerwähnten Dreieck darstellt, sehen, ob es aus einer ungesättigten Lösung bestehen wird, oder ob es das Streben haben wird, sich in eine feste Phase und in eine Lösung $\mathrm{zu}$ spalten; endlich wird man in diesem letzteren Falle sogleich die Zusammensetzung dieser Lösung erkennen, wenn man eine Gerade zieht, die durch B und den das System darstellenden Punkt hindurchgeht, und den Punkt bestimmt, in welchem diese Gerade die Isotherme $\alpha \beta$ trifft. Suchen wir z. B. die Eigenschaften des dem Punkte a (Fig. 3) entsprechenden Systems, so werden wir sogleich sagen können, es sei ein zweiphasisches System, das sich in eine feste Phase, die aus der Komponente B allein besteht, und in eine Lösung von einer Zusammensetzung, die $\mathrm{a}^{\prime}$ entspricht, spalten wird.

Betrachten wir nun ein System, in welchem A Wasser sein mag, C ein Salz, das ein festes Hydrat bildet, und B irgend eine in Wasser lösliche Substanz, und suchen wir für eine gewisse Temperatur, die Gleichgewichtsbedingungen zwischen diesem Hydrat und den wässerigen Lösungen von $\mathrm{C}$ und $\mathrm{B}$. Diese werden bezeichnet durch eine Isotherme, die man auf ähnliche Weise wie die vorhergehende bestimmen kann. Das feste Hydrat wird dargestellt durch einen Punkt an der Seite AC; entsprechend demselben errichten wir eine Senkrechte von einer Länge gleich dem Potential des Hydrats und bestimmen wie im vorhergehenden den Berührungskegel mit der Z-Fläche, die ihren Scheitelpunkt an diesem Punkte hat. Die Projektion der Berührungslinie dieses Kegels ist die gesuchte Isotherme.

An dritter Stelle wollen wir das System betrachten, welches besteht aus Wasser A und aus zwei Substanzen B und C, die in Wasser löslich, aber so beschaffen sind, daß sie sich unter einander verbinden und eine binäre feste Phase bilden können. Der bekannteste diesbezügliche Fall ist der von zwei isomorphen Salzen, die so beschaffen sind, daß sie gemischte Kristalle in allen Konzentrationsverhältnissen bilden können; aber jetzt behandeln wir die Frage von einem allgemeinen Gesichtspunkte aus, ohne uns weiter mit der Natur der Komponenten B und C und der festen anhydrischen Phase, die sie bilden können, zu befassen. Wie gesagt, stellt die Seite BC diese festen Phasen 
dar in allen Konzentrationsverhältnissen. Der Punkt $\alpha$ (siehe Fig. 4) stellt eine gesättigte wässerige Lösung des Bestandteils B allein dar, der Punkt $\beta$ eine gesättigte Lösung des Bestandteils $\mathrm{C}$ allein.

Um die Isotherme $\alpha \beta z u$ bestimmen, welche das Gleichgewicht zwischen einer Lösung $\mathrm{A}+\mathrm{B}+\mathrm{C}$ und einer festen Phase $\mathrm{B}+\mathrm{C}$ definiert, bestimmen wir vor allem den Ort der Potentiale der festen Phasen B $+\mathrm{C}$. Er ist eine in der Ebene $Z B C$ liegende Kurve, welche von den Achsen $B \tau_{-2}$ und $C \tau_{3}$ berührt wird (Fig. 2) und ist, wie Rijn van Alkemade nachgewiesen hat, konvex gegen die Ebene desDreiecks. Ziehen wir durch einen Punkt

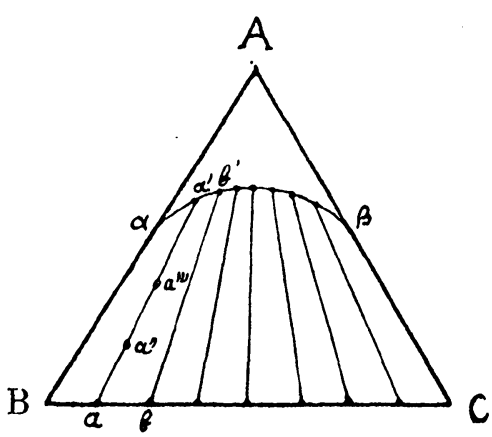

Fig. + . dieser Kurve eine Tangente und durch diese eine Ebene, welche die Potentialfläche berührt, und wiederholen wir dann dieses Verfahren bei allen Punkten der Kurve. Alle diese Berührungsebenen hüllen eine Fläche ein, und die Berührungslinie zwischen dieser Fläche und der Z-Fläche, in der Ebene des Dreiecks projiziert, ist die gesuchte Isotherme.

Aus dieser Konstruktion selbst ersieht man, daß eine Korrespondenz besteht zwischen den Punkten der Isotherme und den Punkten der Achse BC; die einander entsprechenden Punkte heißen konjugierte Punkte; in Fig. 4 sind es z. B. die Punkte a and $a^{\prime}, b$ und $b^{\prime}$ : Konjugationsgeraden heißen diejenigen, welche sie verbinden; sie sind die Projektionen der erzeugenden Linien der abwickelbaren Fläche. Fügen wir hinzu, daß $\alpha$ der konjugierte Punkt von $B$ und $\beta$ der von $C$ ist. Die Paare der konjugierten Punkte stellen die Phasen dar, welche im Gleichgewicht sind: so bezeichnet der Punkt a die feste binäre Phase, welche mit der dreifachen Phase (Lösung) a' im Gleichgewicht ist, der Punkt $b$ die feste Phase, welche mit der Lösung $b^{\prime}$ im Gleichgewicht ist usw.

Die Isotherme $\alpha \beta$ teilt wie oben den Flächeninhalt des ganzen Dreiecks in zwei Felder. Im Felde $\alpha A \beta$ (dem mono- 
phasischen Felde) entsprechen alle Punkte Systemen, die aus einer nicht gesättigten Lösung, weder hinsichtlich $\mathrm{B}$, noch hinsichtlich $\mathrm{C}$, bestehen. Im Felde $\alpha \mathrm{BC} \beta$ (dem zweiphasischen Felde) entsprechen die Punkte labilen Systemen, welche die Neigung haben, sich ins Gleichgewicht zu setzen, indem sie sich in zwei konjugierte Phasen spalten, und insbesondere machen alle Systeme, die einer Konjugationsgeraden entsprechen, Phasen derselben Zusammensetzung, aber in verschiedener Quantität, Platz. Das System a ${ }^{\prime \prime}$ z. B. und das Sytem a ${ }^{\prime \prime \prime}$ werden denselben konjugierten Phasen a und a' Platz machen, aber die Quantität der festen Phase a wird im Vergleich mit der Quantität der Lösung $a^{\prime}$ größer sein für das erste System, als für das zweite.

Die Bedingungen des Gleichgewichts im vorliegenden Falle sind also vollständig bestimmt, wenn man die Isotherme $\alpha \beta$ und die Richtung aller Konjugationsgeraden kennt. In der Tat genügt es, wenn ein Komplex $\mathrm{A}+\mathrm{B}+\mathrm{C}$ gegeben ist, den Punkt zu finden, welcher ihm im Dreieck entspricht, und zu sehen, ob er zum monophasischen oder zum zweiphasischen Felde gehört. Im ersteren Falle wird man schließen können, daß das System aus einer beständigen homogenen Lösung besteht, im letzteren, daß es sich in eine feste Phase und in eine Lösung spalten wird. Bestimmt man alsdann die Konjugationsgerade, welche durch den Punkt selbst geht, so wird man sofort die Zusammensetzung der beiden Phasen erkennen können, wenn man die Punkte bestimmt, in welchen diese Konjugationsgerade die Seite $B C$ und die Isotherme $\alpha \beta$ schneidet.

Diese besonderen Fälle, die ich jetzt beschrieben habe, beziehen sich gerade auf die Gleichgewichte, die ich auf experimentellem Wege studiert habe.

Was das System Eieralbumin $+\mathrm{CuSO}_{4}+\mathrm{H}_{2} \mathrm{O}$ betrifft, so erhält man, wie man bald sehen wird, eine Verbindung der beiden letzten Fälle; das System ist nämlich zuweilen dreiphasisch und besteht aus einer festen Phase, welche durch die Punkte der Achse BG darzustellen ist, aus einem festen Hydrat $\left(\mathrm{CuSO}_{4}+5 \mathrm{H}_{2} \mathrm{O}\right)$, das durch einen Punkt der Achse AC dargestellt wird, und endlich aus einer Lösung, welche durch 
einen Punkt einer Isotherme dargestellt werden kann, deren Äste man in der gewohnten Weise konstruieren kann, indem man nämlich in der Ebene des Dreiecks projiziert: 1. Die Berührungslinie zwischen der z-Fläche und der abwickelbaren Fläche, die mit den Tangentialebenen konstruiert wurde, welche auf die oben beschriebene Weise von den Punkten ausgehen, welche die Potentiale der festen binären Phasen darstellen; 2. die Berührungslinie derselben Fläche mit dem anfangs beschriebenen Berührungskegel, deren Spitze dem Potential des $\mathrm{CuSO}_{4}$-Hydrats entspricht.

Wenn die Kurven einander schneiden, so entsprechen ihre Schnittpunkte (multiplen Punkte) singulären Punkten der z-Fläche, und dann gehen sie zuweilen dazu über, nicht mehr stabile Lösungen, sondern in höherem oder geringerem Grade labile Lösungen darzustellen, die das Streben haben, sich in 2 oder 3 Phasen je nach ihrer Lage zu spalten.

Bei diesen theoretischen Betrachtungen derartiger Probleme wird die Potentialfäche als bekannt vorausgesetzt, und aus ihr werden durch einfache geometrische Operationen die Isothermen abgeleitet, welche die Gleichgewichte bestimmen; in der Praxis folgt man dem umgekehrten Weg, d. h. man bestimmt durch Experimente die Isothermen und die Konjugationsgeraden, und von ihnen kann man später zuweilen auf eine ideale Darstellung der Potentialfläche oder von Teilen derselben wieder zurückgehen. Auf jeden Fall löst diese Bestimmung der Isothermen auf experimentellem Wege das Problem des Gleichgewichts.

Die Methoden, vermittelst welcher die Isothermen erhalten werden können, sind verschieden: ich habe diejenige befolgt, welche in.der Analyse der verschiedenen Phasen besteht, nachdem man sie vorher von einander getrennt hat. Auf diese Weise hat man den Vorteil, auch die Konjugationsgeraden zu erhalten, die bei Verwendung anderer Methoden gewöhnlich unbekannt bleiben.

Untersuchungsmethode.

Wie ich jetzt angedeutet habe, bestand die Mehrzahl der Untersuchungen, über die ich unten ausführlich berichten werde, 
einfach in der Analyse der Lösungen und der Niederschläge. Eine synthetische Methode habe ich nur bei der Untersuchung der labilen Lösungen in Anwendung gebracht.

Bei einigen dieser Untersuchungen habe ich auf die $\mathrm{Zu}$ sammensetzung der Mischungen geachtet, indem ich genau abgemessene Quantitäten von genau bekannten Lösungen von Albumin und Metallsalz vermischte; die Summen der Bestandteile der beiden Phasen mußten dann der miteinander vermischten Menge entsprechen; dieser Vergleich diente mir besonders dazu, mich von der Genauigkeit der Analyse zu überzeugen. So habe ich es beim V. Versuch mit Eieralbumin und $\mathrm{AgNO}_{3}$ gemacht. Bei den anderen aber habe ich dann diese Kontrolle unterlassen, welche die Analysen noch schwieriger und länger machte, weil ich alle Teilchen der Lösung oder des Niederschlages, die in den Gefäßen oder Filtern etc. zurückblieben, sammeln oder berücksichtigen mußte. Deshalb analysierte ich bei allen anderen Experimenten nur einen Teil des Niederschlages und der entsprechenden Lösung, und die Zusammensetzungen der Komplexe, welche man in den folgenden Tabellen finden wird, sind einfach die Summen der durch Analyse der beiden Phasen erhaltenen Zahlen. Die Mischungen wurden in geschlossenen Gefäßen ausgeführt, die 4-6 Stunden lang geschüttelt wurden, um sicher zu sein, daß das Gleichgewicht sich definitiv eingestellt hatte. Hierauf filtrierte ich die Mischung, indem ich dafür Sorge trug, die filtrierte Flüssigkeit zwei- oder dreimal durch das Filter hindurchgehen zu lassen. Wenn das Filtrat, wie es öfters bei den Lösungen geschah, die wenig Metallsalz enthielten, noch trübe war, so zentrifugierte ich es, um jede Flocke des Niederschlages zu entfernen.

Nachdem ich das Filter, das den Niederschlag enthielt, aus dem Trichter entfernt hatte, legte ich den Niederschlag zwischen Filtrierpapier und darauf ein Gewicht, damit es den größten Teil der Lösung, mit welcher der Niederschlag selbst durchtränkt sein konnte, auspreßte. Auf diese Weise erhielt ich eine Art ziemlich festen Teig, den ich genau abwog; ich ließ bei $100^{\circ}$ bis zu konstantem Gewicht trocknen und wog dann wieder. So konnte ich die im Niederschlag zurückge- 
bliebene Menge Wasser kennen lernen und da ich durch die Analyse der Lösung erkannte, wieviel Metallsalz und wieviel Albumin jener Wassermenge entsprach, konnte ich die Resultate der Analyse des Niederschlages leicht korrigieren, sodaß ich die Menge der Substanz erhielt, welche den reinen Niederschlag bildete.

In dieser Hinsicht halte ich es für angezeigt, mich deutlicher durch ein Beispiel auszudrücken. Es sei $P_{n}$ das Gewicht des Niederschlages sogleich nach der Filtration, $\mathrm{P}_{1}$ das Gewicht desselben nach dem Trocknen, so ist folglich

$$
\mathrm{P}_{0}-\mathrm{P}_{1}=\mathrm{W}
$$

das Gewicht des im Niederschlag zurückgebliebenen Wassers.

Aus der Analyse der Lösung, die in Berührung mit diesem Niederschlag war, ergibt sich mir, daß in $W$ Teilen Wassers a Teile Albumin enthalten sind und s Teile Salz. Ist A die Albuminmenge und $\mathrm{S}$ die Salzmenge, die sich mir aus der Analyse des trockenen Niederschlages $\mathrm{P}_{1}$ ergeben, so werden A-a und S-S

die Mengen Albumin und Salz sein, die im reinen Niederschlag enthalten sind. Auf diese Weise konnte ich dem Übelstande abhelfen, daß ich die Niederschläge nicht waschen durfte, da ja, wie gesagt, ein solches Auswaschen die Konzentration des Salzes im Niederschlage selbst herabgesetzt hätte.

Alle diese Manipulationen wurden bei den Experimenten mit $\mathrm{AgNO}_{3}$ im Dunkeln ausgeführt.

Bezüglich der Temperatur will ich nur anführen, daß ich keine Thermostaten während der Zeit verwenden konnte, als die Mischungen sich ins Gleichgewicht setzten, sowie während der Filtration. Ich bin überzeugt, daß in diesen Fällen kleine Temperaturschwankungen keinen großen Einfluß haben können, und andererseits wurden die Experimente, die ich hier beschreiben will, in Jahreszeiten angestellt, während welcher die Temperatur der Umgebung keine großen Schwankungen erlitt, weshalb man sie als konstant zwischen $14^{\circ}$ und $16^{\circ}$ liegend annehmen kann.

Was die Methoden der Analyse betrifft, so will ich nur wenige Worte darüber sagen. Wie ich schon bemerkte, wurden die Niederschläge bis zu einem konstanten Gewicht getrocknet; 
von jedem Filtrat wog ich alsdann eine gewisse Quantität, ließ sie verdunsten und, wie gewöhnlich, trocknete der Rückstand bis zu einem konstanten Gewicht. So lernte ich den Gehalt eines jeden Filtrats an Wasser kennen. Sowohl die trockenen Niederschläge als auch die Rückstände der Filtrate wurden dann sehr sorgfältig allein eingeäschert, hierauf mit $\mathrm{HNO}_{3}$ aufgelöst. In der Lösung bestimmte ich dann das $\mathrm{Cu}$ in Gestalt von $\mathrm{CuO}$ und das $\mathrm{Ag}$ in Gestalt von AgCl. Es hat keinen Zweck, hier ausführlich alle Vorsichtsmaßregeln zu wiederholen, die man bei diesen feinen Manipulationen beobachten muß. Die Albuminmengen wurden durch Differenz erhalten, im Falle der Kupferniederschläge subtrahierte ich aus den oben (S. 506) erwähnten Gründen vom Gesamtgewicht des trockenen Rückstandes das aus dem abgewogenen $\mathrm{CuO}$ berechnete $\mathrm{CuSO}_{4}$, im Falle der Silberniederschläge subtrahierte ich vom Gesamtgewicht des trockenen Rückstandes nur das Gewicht des aus dem gefundenen $\mathrm{AgCl}$ berechneten $\mathrm{Ag}$, insofern als es sicher war, daß in diesen trockenen Rückständen das Ag sich vollständig reduziert befand. Nachdem ich so für die binären Phasen die Mengen der beiden Konstituenten(Albumin-Metallsalz) und für die ternären Phasen die Mengen der drei Konstituenten (Albumin-Metallsalz-Wasser) erhaltenhatte,berechneteich gleich die centesimale Zusammensetzung der beiden Phasen. Ich konnte dann diese Werte nicht auf Verhältnisse von Molekulargewichten zurückführen, wie man das mit Vorteil zu tun pflegt, und zwar weil (wenn man auch die Unsicherheit des Molekulargewichtes der Eiweißkörper nicht in Anschlag bringt) dieses so groß ist, verglichen mit den Gewichten von $\mathrm{CuSO}_{4}$ und $\mathrm{H}_{2} \mathrm{O}$, daß es mir unmöglich gewesen wäre, irgend eine graphische Konstruktion auszuführen. Diese graphischen Darstellungen sind mir dagegen in befriedigender Weise gelungen, als ich einfach die centesimale Gewichtszusammensetzung einer jeden Phase berücksichtigte, gleichseitige Dreiecke von $1 \mathrm{~m}$ per Seite konstruierte und $1 \mathrm{~g}$ einem Centimeter entsprechen ließ. Von den so konstruierten Kurven wurden diejenigen, welche sich auf die Versuche I und II beziehen, später photographiert, um sie auf die nötigen Dimensionen zu reduzieren, während 
diejenigen, welche sich auf die Experimente III, IV und VI beziehen, und die alle im oberen Teile des gleichseitigen Dreiecks enthalten sind, so reproduziert wurden, wie sie vermittelst der Zahlenangaben der vorausgehenden Tabellen konstruiert wurden; natürlich ist in diesen Figuren nur ein Teil des Grunddreiecks dargestellt. Die Metallsalze $\mathrm{CuSO}_{4}$ und $\mathrm{AgNO}_{3}$ wurden mir von der Firma Kahlbaum geliefert. Das Serumalbumin lieferte mir Merk unter der Bezeichnung «ganz rein». Das Serumalbumin, welches mir zu den Experimenten mit $\mathrm{AgNO}_{3}$ diente (Exp. III und IV), wurð̄e zweimal mit Ammoniumsulfat gefällt und der Dialyse unterzogen, sodaß sich nach der Verbrennung desselben im Rückstand nicht einmal Spuren von Chloriden fanden. Das Eieralbumin bereitete ich selbst vermittelst dreier aufeinanderfolgenden Fällungen mit Ammoniumsulfat und angemessener Dialyse. Das kristallisierte Eieralbumin wurde ebenfalls von mir selbst nach der Methode Hopkins und Pinkus $\left({ }^{25}\right)$ bereitet. Die Zahlen, welche die Mengen dieser Eiweißkörper darstellen, sind alle korrigiert worden durch Subtraktion der Aschen, welche sich mir aus geeigneten Bestimmungen ergaben. Im ganz reinen Serumalbumin von Merk (dessen ich mich bei den Experimenten II, III und IV bedient habe) fand ich $0,96 \%$ Aschengehalt, in demselben Serumalbumin nach zwei Fällungen mit Ammoniumsulfat $0,59 \%$; im Eieralbumin, das ich durch Fällung mit Ammoniumsulfat erhielt, fand ich in verschiedenen Präparaten einen verschiedenen Gehalt an Aschenbestandteilen, der von 1-1,3\% schwankte. Im kristallisierten Eieralbumin fand ich nur 0,25\% Aschenbestandteile.

Noch einige Worte will ich hinzufügen über die Zeichen, welche man im Texte und in den Figuren finden wird. Die Spitzen des Dreiecks, welche, wie bereits bemerkt, 100 per 100 einer jeden der drei Bestandteile entsprechen, sind bezeichnet durch die Buchstaben $\mathrm{H}_{2} \mathrm{O}$ (d. h. Wasser), $\mathrm{Al}$ (d. h. Albumin) und $\mathrm{Cu}$ (d. h. $\mathrm{CuSO}_{4}$ ) [resp. Ag bedeutet $\mathrm{AgNO}_{3}$ ].

Die drei Seiten des Dreiecks, welche die drei Achsen dieses Systems von Koordinaten bilden, sind eine jede bestimmt durch die zwei Zeichen, die sich an den entsprechenden Spitzen 
Über d. sog. Metallverbindungen d. Eiweißkörper nach d. Theorie etc. 519

befinden, in eine Klammer eingeschlossen und durch ein Komma getrennt, z. B.: $\left(\mathrm{H}_{2} \mathrm{O}, \mathrm{Al}\right),(\mathrm{Al}, \mathrm{Cu}),\left(\mathrm{Cu}, \mathrm{H}_{2} \mathrm{O}\right)$ und analog für die Systeme mit $\mathrm{AgNO}_{3}$.

Die Punkte des Dreieckinhaltes, welche den Komplexen oder den analysierten stabilen Phasen entsprechen, sind mit großen Anfangsbuchstaben bezeichnet. Die Buchstaben ohne Striche stellen die Komplexe dar, diejenigen mit einem Striche die flüssigen Phasen (Lösungen) und diejenigen mit zwei Strichen die festen Phasen(Niederschläge). Der dem Pentahydrat $\mathrm{CuSO}_{4}+5 \mathrm{H}_{2} \mathrm{O}$ entsprechende Punkt ist durch diese ganze Formel bezeichnet.

Die den labilen Phasen entsprechenden Punkte sind durch griechische Buchstaben bezeichnet.

Im Text sind die verschiedenen Kurvenzweige bezeichnet entweder durch alle Buchstaben, welche sich über ihnen befinden, oder nur durch die beiden, welche sich am Ende eines jeden Zweiges befinden. Die Teile des Flächeninhalts des Dreiecks, die mit gemeinsamen Eigenschaften ausgestattet sind, oder, wie man zu sagen pflegt, die Felder des Dreiecks, sind bezeichnet durch die Buchstaben oder Zeichen, die sich im Umriß des Feldes befinden.

I. Versuch.

System: Eieralbumin $+\mathrm{CuSO}_{4}+\mathrm{H}_{2} \mathrm{O}$.

Die Isotherme, welche $\mathrm{zu}$ diesem System gehört, für eine Temperatur von $14^{0}-16^{\circ}$, ist, wie man aus Fig. 5 ersehen kann, aus drei Kurvenästen zusammengesetzt. Einer der letzteren stellt das Gleichgewicht dar zwischen einer Albumin $\mathrm{CuSO}_{4}$ Lösung und einer festen Phase von Albumin und $\mathrm{CuSO}_{4}$, ein anderer das Gleichgewicht zwischen einer Lösung und dem Hydrat $\mathrm{CuSO}_{4}+5 \mathrm{H}_{2} \mathrm{O}$; endlich stellt der dritte Ast das Gleichgewicht eines dreiphasischen Systems dar, das sich scheidet in eine Lösung, in das oben angeführte Hydrat und in einen Niederschlag. Die drei Äste treffen sich im multiplen Punkte F'.

1. Zweiphasisches System

flüssige Phase: Albumin $+\mathrm{CuSO}_{4}+\mathrm{H}_{2} \mathrm{O}$

feste Phase: Albumin $+\mathrm{CuSO}_{4}$

Der Ast, welcher sich auf das Gleichgewicht dieses Systems bezieht, enthält die Punkte $A^{\prime} B^{\prime} C^{\prime} D^{\prime} E^{\prime} F^{\prime}$. Diese wurden 
erhalten vermittelst der Analyse von Lösungen, welche Mischungen entnommen waren, deren Zusammensetzungen dargestellt sind durch Punkte, die mit denselben Buchstaben bezeichnet sind, aber ohne Striche. Die entsprechenden ebenfalls der Analyse unterworfenen Niederschläge sind dargestellt durch Buchstaben, die auf der (Al, $\mathrm{Cu}$ )-Achse sich befinden. Auf diese Weise konnte ich die Korrespondenz zwischen den Punkten der Isotherme $\mathrm{A}^{\prime} \mathrm{F}^{\prime}$ und den Punkten eines Teils der (Al, Cu)-Achse festsetzen. Diese Korrespondenz wird bestimmt durch die Konjugationsgeraden, welche in der Figur bezeichnet sind. Bei der Betrachtung dieses Astes sieht man, daß er aus einem ansteigenden Zweig besteht, der einen Scheitelpunkt $\mathrm{B}^{\prime}$ in der Nähe der Spitze $\mathrm{H}_{2} \mathrm{O}$ des Dreiecks trifft, und aus einem absteigenden $Z_{w e i g}$, der in $\mathrm{F}^{\prime}$ endet. Der ansteigende Zweig ist, wie man sieht, unvollständig: er sollte die $\left(\mathrm{Al}, \mathrm{H}_{2} \mathrm{O}\right)$-Achse an dem Punkte treffen, der auf dieser Achse die Löslichkeit des Albumins darstellen würde; dieser Punkt ist durchaus unbestimmt. Die Punkte dieses ansteigenden Zweiges stellen Lösungen dar, welche wenig $\mathrm{CuSO}_{4}$ und viel Albumin enthalten und mit Niederschlägen von Albumin und $\mathrm{Cu}$, die auch arm an $\mathrm{Cu}$ sind, im Gleichgewicht sind. Diese zweiphasischen Systeme sind sehr schwer zu behandeln, insofern als die Trennung der beiden Phasen sowohl durch Filtration als auch durch Zentrifugieren sich als sehr schwierig herausstellt. Ich habe vergebens versucht, niedrigere Punkte als $A^{\prime} \mathrm{zu}$ erhalten, d. h. Lösungen im Gleichgewicht mit einer festen Phase, in welcher das Albumin sich in größerer Konzentration befände. Man ersieht aber aus der Richtung des Zweiges $\mathrm{A}^{\prime} \mathrm{B}^{\prime}$, daß die Isotherme einen fast zur $\left(\mathrm{Al}, \mathrm{H}_{2} \mathrm{O}\right)$-Achse parallelen Verlauf nimmt und ganz in ihrer Nähe bleibt.

Fügt man einer durch einen Punkt dieses Zweiges (zwischen $\mathrm{A}^{\prime}$ und $\mathrm{B}^{\prime}$ ) dargestellten Lösung ein wenig $\mathrm{CuSO}_{4}$ hinzu, so ersieht man sofort aus der Figur, daß der Punkt selbst nach rechts hin verschoben wird, d. h. er tritt in das zweiphasische Feld ein, und in der Lösung bildet sich ein Niederschlag. Fügt man dagegen Albumin hinzu, so wird der Punkt nach links verschoben; d. h. gegen das monophasische Feld hin, und die Lösung bleibt als solche bestehen. 
Der Scheitelpunkt der Kurve in $B^{\prime}$ stellt die am meisten verdünnte Lösung (sowohl was das Albumin als das $\mathrm{CuSO}_{4}$ betrifft) dar, welche man im Gleichgewicht mit einer festen Phase erhalten kann. Wie man sieht, ist dieser Scheitelpunkt ganz in der Nähe des Punktes $\mathrm{H}_{2} \mathrm{O}$, was bedeutet, daß in Anwesenheit von viel Wasser sehr kleine Mengen Albumin und $\mathrm{CuSO}_{4}$ genügen, um sich gegenseitig zu beeinflussen und einen Niederschlag zu erzeugen, während dieser nicht mehr eintritt, wenn in derselben Wassermenge die eine oder andere Substanz zunimmt, d. h. wenn der Punkt $B^{\prime}$, während er auf derselben Höhe bleibt, ein wenig nach links oder rechts verschoben wird.

Nimmt man dagegen etwas Wasser durch Verdunstung fort, so wird der Punkt B' nach unten verschoben, d. h. in der Lösung bildet sich ein Niederschlag.

Von $\mathrm{B}^{\prime}$ bis $\mathrm{F}^{\prime}$ sinkt die Kurve, indem sie eine leichte Konvexität nach links hin zeigt. Alle den Punkten dieses Zweiges entsprechenden Lösungen sind ziemlich reich an Albumin. Fügen wir einer dieser Lösungen $\mathrm{CuSO}_{4}$ hinzu, so sieht man, daß der sie darstellende Punkt nach rechts, $d . h$. nach dem monophasischen Felde verschoben wird, und die Lösung verändert sich nicht: fügen wir aber etwas Albuminlösung hinzu, tritt der Punkt in das zweiphasische Feld ein und alsdann erhält man gewöhnlich die Bildung eines Niederschlags. Dies geschieht jedoch nicht immer. In der Tat, wenn wir eine Lösung wählen, die einem Punkte unterhalb $\mathrm{E}^{\prime}$ entspricht, und etwas Albuminlösung hinzufügen, so wird der Punkt nach oben und nach links verschoben; es kann aber sein, daß die Verschiebung nach links nicht dazu hinreicht, daß der Punkt wegen der Konvexität der Kurve in das zweiphasische Feld eintreten kann, d. h. es kann sein, daß man keinen Niederschlàg erhält.

Der Punkt $F^{\prime}$ gehört auch den andern beiden Ästen an, weshalb er später betrachtet werden soll.

Fig. 5 zeigt auch die geregelte Anordnung der Konjugationsgeraden; dies beweist, wie regelmäßig und stetig das Gesetz ist, nach welchem die Konzentration der festen Phasen, d. h. das Verhältnis zwischen ihren beiden Komponenten, von den Konzentrationen der entsprechenden Lösungen abhängt. 
Folgt man der Ordnung der konjugierten Punkte $\mathrm{A}^{\prime} \mathrm{B}^{\prime} \mathrm{C}^{\prime} \mathrm{D}^{\prime}$ in der Isotherme und $\mathrm{A}^{\prime \prime} \mathrm{B}^{\prime \prime} \mathrm{C} / \mathrm{D}^{\prime \prime}$ in $\operatorname{der}(\mathrm{Al}, \mathrm{Cu}$ )-Achse, so sieht man, daß das Gehalt an $\mathrm{Cu}$ des Niederschags um so größer ist, je größer die Konzentration dieses Salzes in der entsprechenden Lösung ist. Die Zusammensetzung der verschiedenen von mir erhaltenen Niederschläge unterscheidet sich nicht sehr von derjenigen, welche andere Autoren gefunden haben, solange wir im ersten Segment (von $\mathrm{Al}$ bis $\mathrm{C}^{\prime \prime}$ ) der (Al, Cu)-Achse bleiben, d. h. solange es sich um Niederschläge im Gleichgewicht mit Lösungen von geringer Konzentration handelt. In der Tat, wenn man die Zahlen der Tabelle 1, welche sich auf die Analysen solcher Niederschläge beziehen, in Prozentsätze von $\mathrm{CuO}$ verwandelt, so erhält man für den Punkt $A / 2,33 \%$ und für den Punkt $B / / 5,59 \%$. Und wenn man so diese Werte und zugleich diejenigen graphisch darstellt, welche von andern Autoren gefunden werden, die wahrscheinlich ebenfalls Lösungen von mittlerer Konzentration verwendeten, so erhält man folgende Reihe.

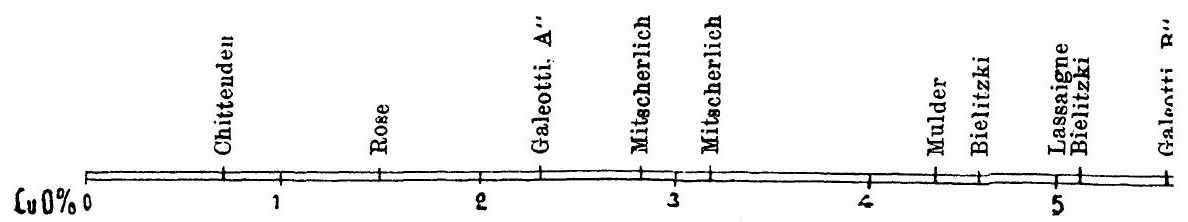

Die Niederschläge dagegen, welche im Gleichgewicht mit Lösungen sind, die viel $\mathrm{CuSO}_{4}$ enthalten, zeigen einen viel größeren Prozentsatz von $\mathrm{Cu}$, wie wir das bei den Punkten $\mathrm{C}^{\prime \prime}$ und $\mathrm{D}^{\prime \prime}$ sehen, bei welchen der Prozentsatz von $\mathrm{CuO}$ die Zahlen 8,25 resp. 20,12 erreicht. Diese Werte steigen dann noch, wenn es sich um gesättigte Lösungen von $\mathrm{CuSO}_{4}$ handelt.

\section{Zweiphasisches System}

flüssige Phase: Albumin $+\mathrm{CuSO}_{4}+\mathrm{H}_{2} \mathrm{O}$ feste Phase: $\mathrm{CuSO}_{4}+5 \mathrm{H}_{2} \mathrm{O}$.

Die Gleichgewichtsbedingungen dieser Systeme, die sich nämlich aus einer Lösung von Albumin und $\mathrm{CuSO}_{4}$ und einem 
Bodensatz von Kristallen dieses Salzes ergeben, sind dargestellt durch die Kurvenstrecke $F^{\prime} L$.

Diese Systeme wurden, wie ich schon erwähnt habe, durch Auflösung einer gewissen Menge Kupferalbuminat in einer in der Hitze gesättigten $\mathrm{CuSO}_{4}$-Lösung erhalten, die ich dann bis auf $35^{\circ}$ erkalten gelassen hatte.

Die klare Flüssigkeit wurde sogleich filtriert, dann ließ ich sie weiter bis auf $14^{\circ}-16^{\circ}$ erkalten und impfte hierauf mit einigen kleinen Kristallen von $\mathrm{CuSO}_{4}$. Nach 24-48 Stunden bildete sich ein Bodensatz von schönen Kristallen, welche sogar eine Länge von 4 oder $5 \mathrm{~mm}$ erreichten und im allgemeinen in Bündeln oder sternartig angeordnet waren.

Die Flüssigkeit, welche sich vollkommen klar erhalten hatte (wenn die Menge des Albumins sehr groß war, so erhielt man gleichzeitig mit der Kristallbildung die Bildung eines Niederschlags, d. h. das System wurde dreiphasisch, wie wir bald sehen werden), wurde von den Kristallen durch Dekantierung und Filtrieren getrennt und der Analyse unterzogen. Die sehr schnell mit gesättigter $\mathrm{CuSO}_{4}$-Lösung gewaschenen und abgetrockneten Kristalle wurden gewogen.

Dieser Ast der Isotherme (Fig. 5) hat das Aussehen eines kurzen Kreisbogens und trifft im Punkte $F^{\prime}$ die anderen beiden Äste. Es könnte sein, daß er links von $\mathrm{F}^{\prime}$ unterhalb des Astes $\mathrm{H}^{\prime} \mathrm{F}^{\prime}$ weiter ginge und dann würde er labile Lösungen darstellen; hier gelang es mir aber nicht, irgend einen Punkt zu bestimmen.

Der Punkt $\mathrm{L}$ stellt eine gesättigte reine $\mathrm{CuSO}_{4}$-Lösung dar oder besser eine Lösung im Gleichgewicht mit dem Hydrat $\mathrm{CuSO}_{4}+5 \mathrm{H}_{2} \mathrm{O}$. Fügt man einer durch einen Punkt dieser Kurve dargestellten Lösung etwas Wasser hinzu, so wird der Punkt in die Höhe geschoben, d. h. er tritt in das monophasische Feld ein und deshalb erhält man keinen Niederschlag. Die Geraden, welche die Punkte der Kurve mit dem Punkt $\mathrm{CuSO}_{4}+5 \mathrm{H}_{2} \mathrm{O}$ verbinden, enthalten Punkte, welche Komplexe darstellen, die sich alle in eine Lösung von gleicher Zusammensetzung und in eine größere oder kleinere Menge Kristalle spalten, je nachdem der Punkt sich tiefer oder höher auf den Geraden selbst befindet. 


\section{Dreiphasisches System}

flüssige Phase: Albumin $+\mathrm{CuSO}_{4}+\mathrm{H}_{2} \mathrm{O}$

1. feste Phase: Albumin $+\mathrm{CuSO}_{4}$

2. feste Phase: $\mathrm{CuSO}_{4}+5 \mathrm{H}_{2} \mathrm{O}$.

Löst man eine große Menge Kupferalbuminat in einer übersättigten $\mathrm{CuSO}_{4}$-Lösung auf, wie vorher erwähnt wurde, und läßt dann die Flüssigkeit unter einer Glocke mit $\mathrm{H}_{2} \mathrm{SO}_{4}$ etwas verdunsten, so erhält man zuerst nur Erzeugung von Kristallen und die Flüssigkeit bleibt klar, dann wird die Flüssigkeit allmählich, sowie die Kristalle anwachsen, trüb, und endlich sinkt ein mehr oder weniger reichlicher Niederschlag zu Boden; diesen Niederschlag kann man mit großer Vorsicht von den Kristallen und der zurückbleibenden Flüssigkeit trennen.

Die Gleichgewichtsbedingungen dieser dreiphasischen Systeme sind in einem solchen Falle dargestellt durch den Kurvenast $\mathrm{H}^{\prime} \mathrm{F}^{\prime}$. Man sieht sogleich, daß dieser Ast nicht eine Fortsetzung des Astes $\mathrm{F}^{\prime} \mathrm{L}$ ist, und in der Tat sind die Gleichgewichtsbedingungen links und rechts von $\mathrm{F}^{\prime}$ sehr verschieden und der Unterschied besteht gerade in der Gegenwart einer neuen Phase.

Die Kurve $\mathrm{H}^{\prime} \mathrm{F}^{\prime}$ scheint sehr regelmäßig zu sein. Es ist unmöglich, das äußerste Ende nach links hin (jenseits des Punktes $H^{\prime}$ ) zu bestimmen, weil die Lösungen mit großen Mengen Albumin so dick werden, daß man sie nicht mehr von den festen Phasen trennen kann.

Fügt man einer durch einen Punkt dieser Kurve dargestellten Lösung Wasser hinzu, so verschiebt sich der Punkt nach oben, d. h. er tritt in das zweiphasische Feld ein, und man erhält einen neuen Niederschlag. Fügt man dagegen Wasser und $\mathrm{CuSO}_{4}$ in genügender Menge hinzu, so daß man den Punkt nach rechts und oben verschiebt, bis er in das monophasische Feld oberhalb des Astes F'L eintritt, so erhält man keinen Niederschlag. Läßt man sodann die so geänderte Lösung etwas verdunsten, so daß der sie darstellende Punkt unterhalb $\mathrm{F}^{\prime} \mathrm{L}$ geht, so erhält man eine Bildung von $\mathrm{CuSO}_{4}$-Kristallen, ohne irgendwelchen Niederschlag. Die Punkte $\mathrm{H}^{\prime} \mathrm{G}^{\prime} \mathrm{F}^{\prime}$ dieses Astes haben eine doppelte Korrespondenz. Sie sind nämlich konjugiert mit 
Punkten, die auf der $(\mathrm{Al}, \mathrm{Cu})$-Achse sich befinden und diefesten im Gleichgewicht mit den oben erwähnten Lösungen stehenden Phasen darstellen und entsprechen ebenfalls dem Punkte $\mathrm{CuSO}_{4}+5 \mathrm{H}_{2} \mathrm{O}$.

Die Konjugationsgeraden $\mathrm{H}^{\prime /} \mathrm{H}^{\prime}, \mathrm{G}^{\prime \prime} \mathrm{G}^{\prime}, \mathrm{F}^{\prime /} \mathrm{F}^{\prime}$ haben eine andere Richtung als die Konjugationsgeraden, die sich auf das erste zweiphasische System beziehen. Sie zeigen aber auch, daß an Albumin reicherenLösungen Niederschläge entsprechen, welche ebenfalls einen größeren Albumingehalt haben und umgekehrt, aber das ,Maß, in welchem das Verhältnis zwischen den beiden Komponenten Albumin und $\mathrm{CuSO}_{4}$ im Niederschlag variiert, ist geringer als dasjenige, in welchem dieses Verhältnis in der Lösung variiert, während sich beim zweiphasischen System das Gegenteil zeigt. In der Tat, wenn wir einen Punkt sich längs der Kurve $\mathrm{H}^{\prime} \mathrm{F}^{\prime}$ bewegen lassen, so durchläuft, während er diesen ganzen Ast durchläuft, der ihm konjugierte Punkt nur die kleine Strecke $\mathrm{H}^{\prime /} \mathrm{F} /$.

Die Punkte, welche die Komplexe darstellen, die sich in die drei von uns betrachteten Phasen spalten, befinden sich im allgemeinen auf keiner der beiden Geraden, welche eine Lösung mit den beiden ihr entsprechenden festen Phasen verbinden, sondern sie befinden sich zwischen den beiden Geraden in einer Lage, die durch ein Gesetz bestimmt wird, das sich nicht leicht auf experimentellem Wege erfinden läßt. Man kann nur soviel sagen, daß, wenn wir uns vorstellen, die Menge des Niederschlages werde unendlich klein gegenüber der Menge der Lösung und der Kristalle, der den Komplex darstellende Punkt sich in der Geraden befinden wird, welche die Lösung mit dem Punkte $\mathrm{CuSO}_{4}+5 \mathrm{H}_{2} \mathrm{O}$ vereinigt; stellen wir uns dagegen vor, die Menge der Kristalle werde unendlichklein gegenüber den Mengen der Lösung und des Niederschlages, so wird der den Komplex darstellende Punkt sich in der Konjugationsgeraden befinden.

Die Resultate der Analyse der verschiedenen Phasen in allen diesen drei Arten des Gleichgewichtes sind in der folgenden Tabelle zusammengefaßt, in welcher sich auch die centesimalen Zusammensetzungen jeder einzelnen Phase und ihrer Komplexe befinden. Diese letzteren Zahlen sind die Koordinaten der Punkte, welche zur Zeichnung der Isothermen der Fig. 5 dienten.

Hoppe-Seyler's Zeitschrift f. physiol. Chemie. XL. 
Tabelle I (deI

System: Eier:

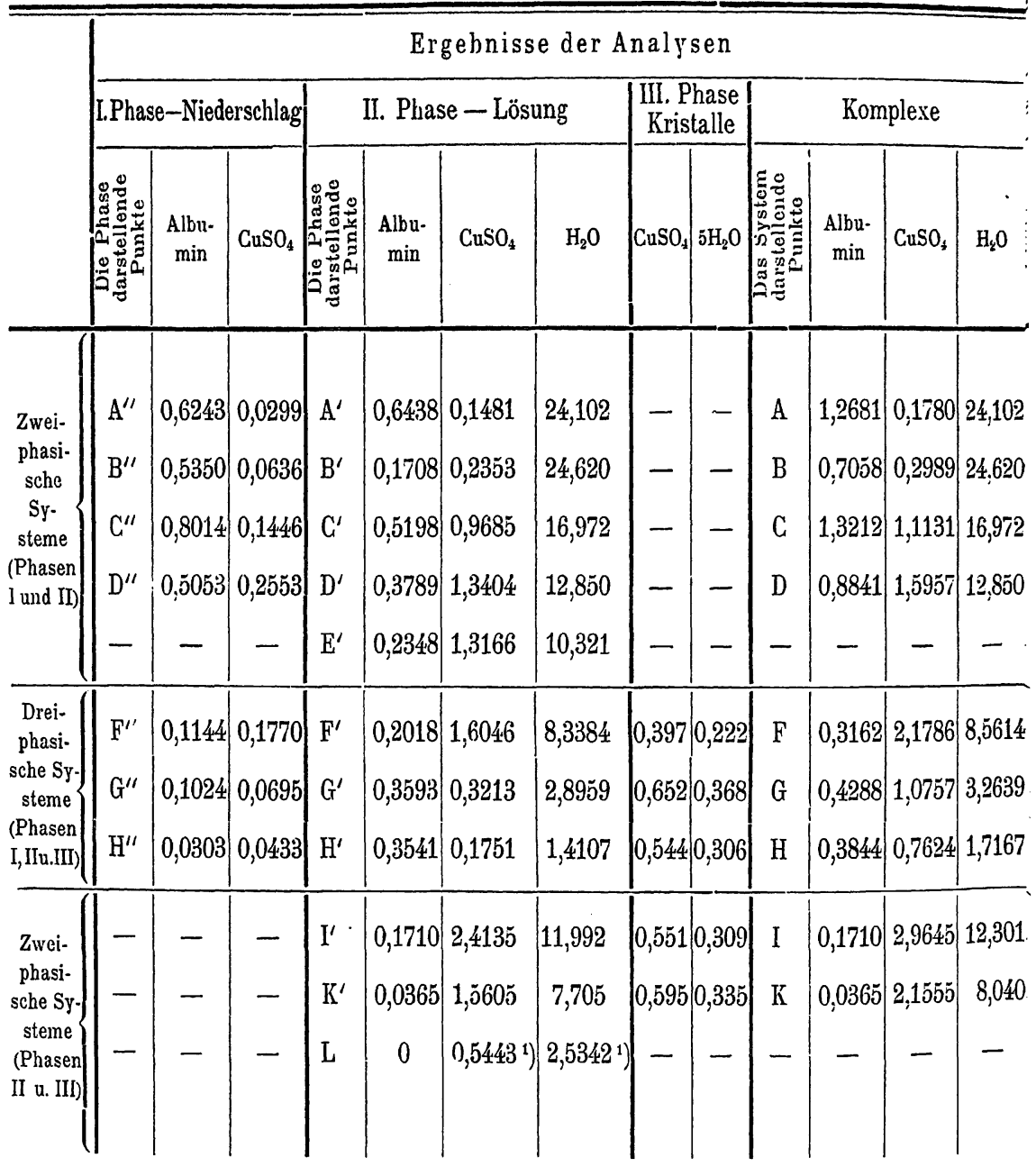

1) Diese Zahlen stellen die Löslichkeit des $\mathrm{CuSO}_{4}$ dar, wie sie sich mir ergab aus einer der: hatte, die ich dann unter denselben Bedingungen hatte kristallisieren lassen, unter welchen; dem Zeichen I wiederholt. In dieser Hinsicht muß ich bemerken, daß in der Literatur beperatur von $19^{\circ}$ betrifft, so gibt Poggiale 18,90\% an und Etard 16,56\%. 
Über d. sog. Metallverbindungen d. Eiweißkörper nach d. Theorie etc. 527

ig. 5 entsprechend).

abumin $+\mathrm{CuSO}_{4}+\mathrm{H}_{2} \mathrm{O}$.

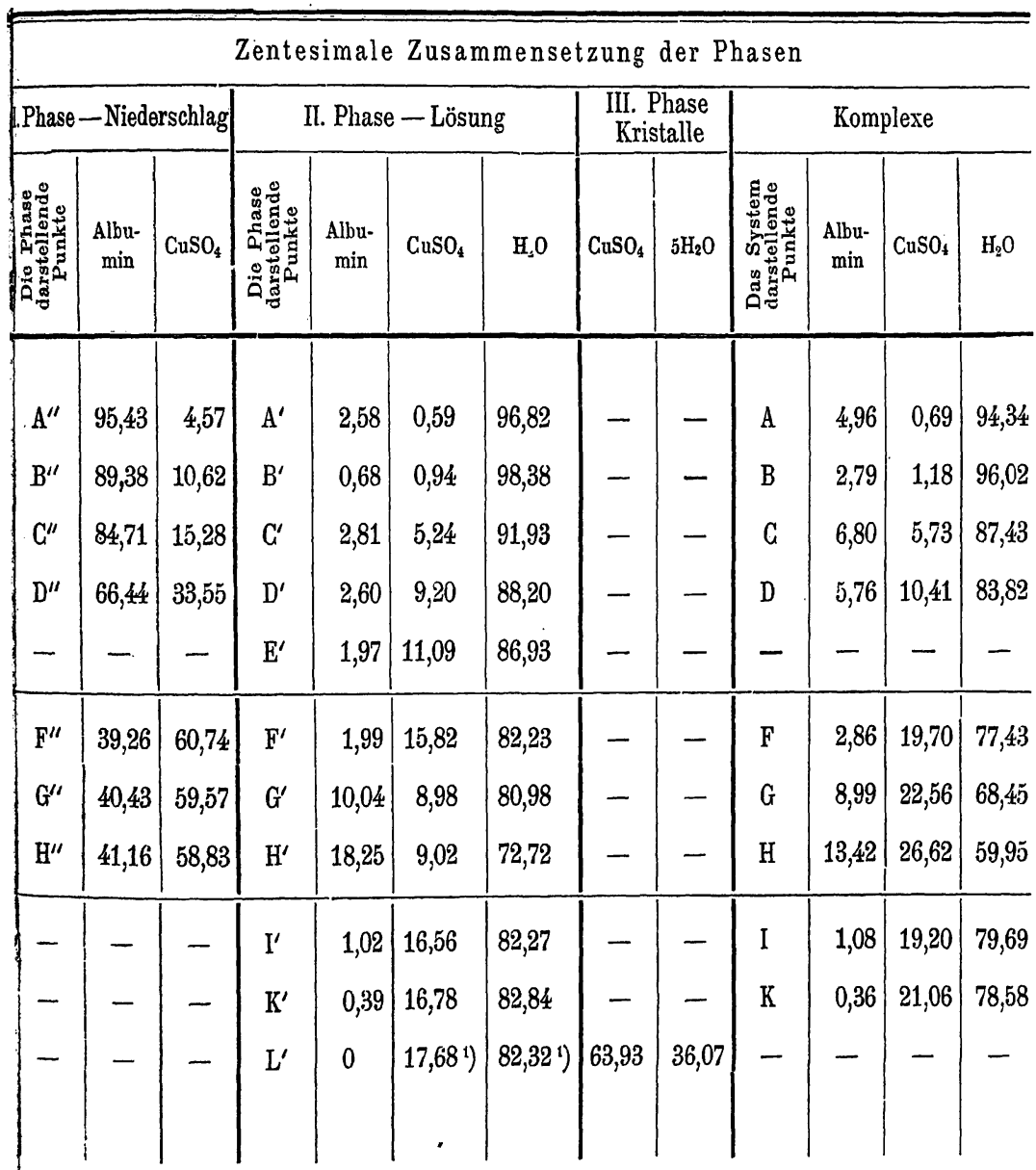

rerschiedenen Bestimmungen, welche ich bei einer in der Hitze übersättigten Lösung gemacht ich die Albumin enthaltenden Lösungen hielt. Sie sind in der folgenden Tabelle entsprechend thächtliche Verschiedenheiten bezüglich der Löslichkeit dieses Salzes bestehen. Was die Tem- 
Wenn man zusammenfasst, was ich bis jetzt auseinandergesetzt habe, so sieht man, wie die von mir gezeichneten Kurven die allgemeinen Bedingungen des Gleichgewichtes des für die Temperatur, auf welche die Isotherme sich bezieht, in Betracht gezogenen Systems bestimmen. Die drei Kurvenäste $\mathrm{A}^{\prime} \mathrm{F}^{\prime}, \mathrm{LF}^{\prime}$ und $\mathrm{H}^{\prime} \mathrm{F}^{\prime}$ teilen den ganzen Flächeninhalt des Dreiecks, der die unendlich möglichen Komplexe des Systems durch seine Punkte darstellt, in vier Felder.

Das erste Feld, das monophasische, ist unten begrenzt durch die beiden Äste $\mathrm{A}^{\prime} \mathrm{F}^{\prime}$ und $\mathrm{F}^{\prime} \mathrm{L}$, oben durch Teile der beiden Seiten des Dreiecks. Dieses Feld ist überall geschlossen und nur nach links geöffnet, wo es durch das Zusammentreffen der Kurve $\mathrm{A}^{\prime} \mathrm{F}^{\prime}$ mit der ( $\mathrm{Al}, \mathrm{H}_{2} \mathrm{O}$ )-Achse begrenzt sein sollte; aber dieser Punkt bleibt, wie ich gesagt habe, unbestimmt. Jeder beliebige Komplex, welcher einem Punkte dieses Feldes entspricht, ist und bleibt beständig eine Lösung.

Das zweite Feld, ein zweiphasisches, hat die Gestalt eines Sektors und wird oben begrenzt durch die Kurve F/L, rechts durch einen Teil der rechten Seite des Dreiecks, d. h. durch die Strecke $\mathrm{CuSO}_{4}+5 \mathrm{H}_{2} \mathrm{O}$, L, links durch die Gerade, welche den Punkt $\mathrm{CuSO}_{4}+5 \mathrm{H}_{2} \mathrm{O}$ mit $\mathrm{F}^{\prime}$ verbindet. Jeder beliebige Punkt im Innern desselben stellt einen Komplex dar, der das Streben hat, sich in eine Lösung und in eine gewisse Menge Kupfersulfatkristalle zu spalten. Ein drittes zweiphasisches Feld ist oben begrenzt durch die Kurve $\mathrm{A}^{\prime} \mathrm{F}^{\prime}$, unten rechts durch die Kurve $\mathrm{F}^{\prime} \mathrm{H}^{\prime}$, links durch einen Teil der $\left(\mathrm{Al}, \mathrm{H}_{2} \mathrm{O}\right)$-Achse und durch einen Teil der (Al, $\mathrm{Cu}$ )-Achse. Rechts bleibt jedoch die Grenze des Feldes zwischen dieser letzteren Achse und dem Punkte $\mathrm{H}^{\prime}$ unbestimmt. Ein Komplex, der einem beliebigen Punkte dieses Feldes entspricht, spaltet sich in zwei Phasen, nämlich in eine Lösung und in einen Niederschlag von Albumin und $\mathrm{Cu}$; die Zusammensetzung dieser beiden Phasen wird bestimmt durch die Konjugationsgerade, welche durch den Punkt selbst geht.

Das vierte Feld endlich, ein dreiphasisches, ist oben begrenzt durch die Kurve $\mathrm{H}^{\prime} \mathrm{F}^{\prime}$, rechts durch die Gerade $\mathrm{F}^{\prime}, \mathrm{CuSO}_{4}$ $+5 \mathrm{H}_{2} \mathrm{O}$, unten durch einen Teil der $(\mathrm{Al}, \mathrm{Cu})$-Achse. Links grenzt 
es an das im vorhergehenden beschriebene Feld, aber die Grenze selbst läßt sich nicht bestimmen. Ein Komplex, der einem beliebigen Punkte dieses Feldes entspricht, spaltet sich in die drei folgenden Phasen: Lösung • - Kristalle - Niederschlag von Albumin und Cu. Zuletzt bleibt ein Teil des Dreiecks übrig, in bezug auf welchen man keine Voraussetzung aussprechen kann. Er liegt gegen den Scheitelpunkt Cu des Dreiecks hin unterhalb des Punktes, welcher das Pentahydrat darstellt.

Außerhalb dieses Teiles aber ist das Gleichgewicht überall bestimmt, und wenn ein Komplex von bestimmter Zusammensetzung gegeben ist, so wird es genügen, den Punkt zu finden, der ihn innerhalb des Dreiecks darstellt, und seine Lage gegenüber den Ästen der schon entworfenen Isotherme und den Konjugationsgeraden $\mathrm{zu}$ beachten, um gleich feststellen $\mathrm{zu}$ können, in wieviel Phasen er sich spalten wird, wenn er sich ins Gleichgewicht setzt, und welches die Zusammensetzung der einzelnen Phasen sein wird.

\section{Versuch.}

System: Serumalbumin $+\mathrm{CuSO}_{4}+\mathrm{H}_{2} \mathrm{O}$.

Die Gleichgewichtszustände dieses Systems, bei einer Temperatur von $14^{0}-16^{0}$, sind durch zwei Kurven bestimmt (siehe Fig. 6), die sich wahrscheinlich an einem Punkte treffen. Von diesen zwei Kurven stellt die eine das Gleichgewicht zwischen einem Kupferalbuminat und einer Lösung dar, die andere das Gleichgewicht zwischen $\mathrm{CuSO}_{4}$-Krystallen und einer Lösung. In diesem Falle gelang es mir nicht, dreiphasische Komplexe zu erhalten, und die gesättigten und viel Albumin enthaltenden $\mathrm{CuSO}_{4}$-Lösungen blieben immer klar, auch wenn sie durch Verdunstung viel Wasser verloren, große Menge,von Krystallen am Boden absetzen und sehr dick und schleimig wurden.

\section{Zweiphasisches System}

flüssige Phase: Albumin $+\mathrm{CuSO}_{4}+\mathrm{H}_{2} \mathrm{O}$

feste Phase: Albumin $+\mathrm{CuSO}_{4}$.

Die Kurve, welche diese Gleichgewichtszustände bestimm, enthält (Fig. 6) die Punkle $A^{\prime} B^{\prime} C^{\prime} D^{\prime} E^{\prime} F^{\prime} G^{\prime}$. Die Komplexe 
$A B C D$, welchen die den Punkten $A^{\prime} B^{\prime} C^{\prime} D^{\prime}$ entsprechenden Lösungen entnommen wurden, ergaben sich durch einfache Mischung von Lösungen von Albumin und $\mathrm{CuSO}_{4}$, in verschiedenen Konzentrationen; die Komplexe EFG dagegen wurden vermittelst Verdünnung konzentrierter Lösungen von Albumin und $\mathrm{CuSO}_{4}$ erhalten, weil, wie bereits beim vorhergehenden Experimente bemerkt wurde, diese konzentrierten Lösungen bei Verdünnung durch Wasser-einem Niederschlag Platz machen.

Es gelang mir nicht, tiefere Punkte als $G^{\prime}$ zu bestimmen, nicht weil man keine mehr als $G^{\prime}$ konzentrierten Lösungen erhalten kann, die im Gleichgewicht mit einem Niederschlag sind, sondern weil infolge der Dicke solcher Lösungen die Filtration unmöglich wird. Daher habe ich die Kurve unterhalb G' (in Fig. 6 ist diese Strecke punktiert gezeichnet) ideal fortgesetzt, und es ist höchst wahrscheinlich, daß dies ihr wirklicher Verlauf ist, wie es auch sehr wahrscheinlich ist, daß sie die andere Kurve in $\alpha$ trifft, wie man es in der Figur sieht.

Der Verlauf der Kurven von $A^{\prime}$ bis $G^{\prime}$ unterscheidet sich nicht wesentlich von der dem Eieralbumin entsprechenden Isotherme. Auch hier gibt es einen ansteigenden Zweig, von dem es mir nur möglich war, ein kurzes Segment zu zeichnen, aus dem man jedoch ersieht, daß die Kurve das Streben hat, sich immer mehr der $\left(\mathrm{Al}, \mathrm{H}_{2} \mathrm{O}\right)$-Achse zu nähern, die sie dann im (unbestimmten) Punkte treffen sollte, welches die Löslichkeit des Serumalbumins darstellen würde.

Sodann erhält man einen Scheitelpunkt in $B^{\prime}$ und einen absteigenden Zweig, der beinahe einen geradlinigen Verlauf zeigt.

Die Punkte $\mathrm{A}^{\prime} \mathrm{B}^{\prime} \mathrm{C}^{\prime} \mathrm{D}^{\prime} \mathrm{E}^{\prime} \mathrm{F}^{\prime} \mathrm{G}^{\prime}$ sind konjugiert mit den Punkten $\mathrm{A}^{\mathrm{A}} \mathrm{B}^{\prime \prime} \mathrm{C}^{\prime \prime} \mathrm{D}$ "E $\mathrm{E}^{\prime} \mathrm{F}$ "G", welche sich auf der (Al, $\mathrm{Cu}$ )-Achse befinden, und diese stellen die Zusammensetzung der Niederschläge dar, die im Gleichgewicht mit den verschiedenen Lösungen sind. Die Konjugationsgeraden haben eine sehr regelmäßige Anordnung und sind fast einander parallel. Sie beweisen, dab, wie es auch sein muß, in der Tat eine eindeutige Korrespondenz zwischen der Zusammensetzung des Niederschlages und derjenigen der Lösung besteht. Viel Albumin und wenig $\mathrm{CuSO}_{4}$ enthaltenden Lösungen entsprechen Niederschläge, die auch arm 
an diesem Salz sind und umgekehrt, und das Verhältnis zwischen Albumin und $\mathrm{Cu}$ variiert mit einer gewissen Gleichförmigkeit in den Lösungen und in den entsprechenden Niederschlägen.

Zieht man dem Verlaufe der in der Figur gezeichneten Konjugationsgeraden folgend andere durch die Punkte des punktierten Segments der Kurve, so erscheint es klar, daß sie die (Al, $\mathrm{Cu}$ )-Achse an Punkten treffen würden, die mehr rechts von $G^{\prime \prime}$ liegen; dies bedeutet, daß Niederschläge von Serumalbumin und $\mathrm{Cu}$ auftreten können, welche dieses Element auch in größerem Verhältnis enthalten können, als ich es bei den von mir gemachten Analysen gefunden habe. Aus Fig. 6 ersieht man auch, daß die letzte Konjugationsgerade, diejenige, welche vom PPunkte $\alpha$ ausgehen würde, mit aller Wahrscheinlichkeit als Tangente der Kurve $M / I$ verlaufen müßte: mithin wäre wahrscheinlich der Punkt $\alpha$ der einzige dreiphasische Punkt des Systems.

\section{Zweiphasisches System}

flüssige Phase: Albumin $+\mathrm{CuSO}_{4}+\mathrm{H}_{2} \mathrm{O}$

feste Phase: $\mathrm{CuSO}_{4}+5 \mathrm{H}_{2} \mathrm{O}$

Die Gleichgewichtsbedingungen in diesem System sind durch die Kurve M/I (Fig. 6) dargestellt. Die Punkte dieser Kurve wurden durch die Analyse von Lösungen ermittelt, die ich durch Auflösung eines Kupferalbuminates in übersättigter $\mathrm{CuSO}_{4}$-Lösung erhalten hatte. Auf diese Weise kann man Lösungen erzeugen, die sehr reich an Serumalbumin sind, sich klar aufbewahren lassen, sehr lichtbrechend und von schöner smaragdgrüner Farbe sind. Sie werden immer dichter durch Ver-. dunstung und setzen schöne $\mathrm{CuSO}_{4}$-Kristalle auf dem Boden ab.

Die konzentrierteste unter diesen Lösungen, welche ich der Analyse unterzogen habe, ist diejenige, welche dem Punkte $\mathrm{M}^{\prime}$ entspricht, und hier ist die Kurve unterbrochen, zeigt aber schon das Streben, sich fast senkrecht nach unten zu wenden, und hat deshalb einen ganz anderen Verlauf, als die entsprechende Kurve für das Eieralbumin.

Der Punkt $\alpha$, der, wie ich sagte, wahrscheinlich der Punkt ist, an welchem sich die beiden Kurven treffen, teilt die jetrt betrachtete Kurve in zwei Teile, und die Punkle dieser zwei 


\begin{tabular}{|c|c|c|c|c|c|c|c|c|c|c|c|c|c|}
\hline & \multicolumn{13}{|c|}{ Ergebnisse der Anaiyse } \\
\hline & \multicolumn{3}{|c|}{ I.Phase-Niederschlag } & \multicolumn{4}{|c|}{ II. Phase - Lösung } & \multicolumn{2}{|c|}{$\begin{array}{l}\text { III. Phase } \\
\text { Kristalle }\end{array}$} & \multicolumn{4}{|c|}{ Komplexe } \\
\hline & 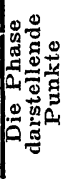 & $\begin{array}{c}\text { Albu- } \\
\text { min }\end{array}$ & $\mathrm{CuSO}_{4}$ & 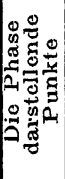 & $\begin{array}{c}\text { Albu- } \\
\text { min }\end{array}$ & $\mathrm{CuSO}_{4}$ & $\mathrm{H}_{2} \mathrm{O}$ & $\mathrm{CuSO}_{4}$ & $5 \mathrm{H}_{2} \mathrm{O}$ & 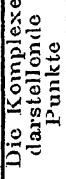 & $\begin{array}{c}\text { Albu. } \\
\min \end{array}$ & $\mathrm{CuSO}_{4}$ & $\mathrm{H}_{2} \mathrm{O}$ \\
\hline & $\mathrm{A}^{\prime \prime}$ & 0,3686 & 0,0136 & $\mathrm{~A}^{\prime}$ & 0,6421 & 0,1134 & 37,0012 & - & - & A & 1,0107 & 0,2270 & 37,0012 \\
\hline 1. zwei- & $\mathrm{B}^{\prime \prime}$ & 0,4505 & 0,0149 & $\mathrm{~B}^{\prime}$ & 0,2704 & 0,1078 & 26,730 & - & - & B & 0,7209 & 0,1227 & 26,730 \\
\hline sches & $\mathrm{C}^{\prime \prime}$ & $0,25 \check{19}$ & 0,0225 & $C^{\prime}$ & 0,1992 & 0,3986 & 24,317 & - & - & $\mathrm{C}$ & 0,4511 & 0,4211 & 24,317 \\
\hline Sy- & $\mathrm{D}^{\prime \prime}$ & 0,1703 & 0,0178 & $D^{\prime}$ & 0,1426 & 0,4948 & 16,368 & - & - & D & 0,3129 & 0,5126 & 16,368 \\
\hline (Phasen & $\mathrm{E}^{\prime \prime}$ & 0,2873 & 0,0486 & $\mathrm{E}^{\prime}$ & 0,2044 & 0,8433 & 17,906 & - & - & $\mathrm{E}$ & 0,4917 & 0,8919 & 17,903 \\
\hline & $F^{\prime \prime}$ & 0,1987 & 0,0436 & $F^{\prime}$ & 0,1391 & 0,6677 & 8,4575 & - & - & $\mathrm{F}$ & 0,3378 & 0,7113 & 8,4575 \\
\hline & $G^{\prime \prime}$ & 0,1501 & 0,0513 & $G^{\prime}$ & 0,1113 & 0,6573 & 6,231 & - & - & G & 0,2614 & 0,7086 & 6,231 \\
\hline & - & - & - & $I$ & 0 & 0,5443 & 2,5342 & - & - & - & - & - & - \\
\hline phasi- & - & - & - & $\mathrm{H}^{\prime}$ & 0,2980 & 2,1283 & 9,1372 & 0,620 & 0,350 & $\mathrm{H}$ & 0,2980 & 2,7483 & 9,4872 \\
\hline $\begin{array}{l}\text { sches } \\
\text { Sy. }\end{array}$ & - & - & - & $\mathrm{K}^{\prime}$ & $0, \overline{0} 651$ & 2,8910 & 12,0375 & 0,670 & 0,380 & $\mathrm{~K}$ & 0,5651 & 3,5610 & 12,4175 \\
\hline stem & - & - & - & $\mathrm{L}^{\prime}$ & 0,6009 & 2,2631 & 9,2176 & 0,703 & 0,397 & $\mathrm{~L}$ & 0,6009 & 2,9661 & 9,6146 \\
\hline II u. III) & - & - & - & $M^{\prime}$ & 0,4489 & $0,947.1$ & 2,9960 & 0,326 & 0,184 & M & 0,4489 & 1,2731 & 3,1800 \\
\hline
\end{tabular}


Fig. 6 entsprechend).

albumin $+\mathrm{CuSO}_{4}+\mathrm{H}_{2} \mathrm{O}$.

Zentesimale Zusammensetzungen der Phasen

\begin{tabular}{|c|c|c|c|c|c|c|c|c|c|c|c|c|}
\hline \multicolumn{3}{|c|}{ L. Phase - Niederschlag } & \multicolumn{4}{|c|}{ II. Phase - Lösung } & \multicolumn{2}{|c|}{$\begin{array}{c}\text { III. Phase } \\
\text { Kristalle }\end{array}$} & \multicolumn{4}{|c|}{ Komplexe } \\
\hline 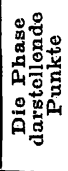 & $\begin{array}{c}\text { Albu- } \\
\min \end{array}$ & $\mathrm{CuSO}_{4}$ & 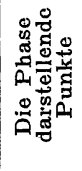 & $\begin{array}{c}\text { Albu- } \\
\min \end{array}$ & $\mathrm{CuSO}_{4}$ & $\mathrm{H}_{2} \mathrm{O}$ & $\mathrm{CuSO}_{4}$ & $\mathrm{H}_{2} \mathrm{O}$ & 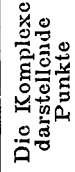 & $\begin{array}{c}\text { Albu- } \\
\min \end{array}$ & $\mathrm{CuSO}_{4}$ & $\mathrm{H}_{2} \mathrm{O}$ \\
\hline $\mathrm{A}^{\prime \prime}$ & 96,44 & 3,55 & $\mathrm{~A}^{\prime}$ & 1,70 & 0,30 & 98,00 & - & - & A & 2,64 & 0,59 & 96,76 \\
\hline $\mathrm{B}^{\prime \prime}$ & 96,80 & 3,20 & $\mathrm{~B}^{\prime}$ & 0,99 & 0,39 & 98,61 & - & - & B & 2,61 & 0,44 & 96,94 \\
\hline $\mathrm{C}^{\prime \prime}$ & 91,77 & 8,19 & $\mathrm{C}^{\prime}$ & 0,79 & 0,60 & 97,60 & - & - & C & 1,79 & 1,67 & 96,004 \\
\hline $\mathrm{D}^{\prime \prime}$ & 90,54 & 9,46 & $\mathrm{D}^{\prime}$ & 0,84 & 2,91 & 96,25 & - & - & $D$ & 1,82 & 2,98 & 95,14 \\
\hline $\mathrm{E}^{\prime \prime}$ & 85,53 & 14,47 & $\mathrm{E}^{\prime}$ & 1,07 & 4,47 & 94,47 & - & - & $\mathrm{E}$ & 2,55 & 4,62 & 92,83 \\
\hline$F^{\prime \prime}$ & 82,01 & 17,99 & $\mathrm{~F}^{\prime}$ & 1,50 & 7,20 & 91,30 & - & - & $\mathrm{F}$ & $3, \check{55}$ & 7,48 & 88,96 \\
\hline$G^{\prime \prime}$ & 74,53 & 25,47 & $G^{\prime}$ & 1,59 & 9,39 & 89,02 & - & - & G & 3,63 & 9,84 & 86,53 \\
\hline- & - & - & I & 0 & 17,68 & 82,32 & 63,93 & 36,07 & - & - & - & - \\
\hline- & - & - & $\mathrm{H}^{\prime}$ & 2,75 & 18,41 & 79,01 & - & - & $\mathrm{H}$ & 2,37 & 21,93 & 75,70 \\
\hline- & - & - & $\mathrm{K}^{\prime}$ & 3,64 & 18,66 & 77,69 & - & - & K & 3,41 & 21,53 & 75,06 \\
\hline - & - & - & $\mathrm{L}^{\prime}$ & 4,98 & 18,78 & 76,47 & - & - & $L$ & 4,55 & 22,49 & 72,94 \\
\hline- & - & - & $M^{\prime}$ & \begin{tabular}{|l}
10,22 \\
\end{tabular} & 21,56 & 68,21 & - & - & M & 9,15 & 25,97 & 664,87 \\
\hline
\end{tabular}


T'eile haben verschiedene Eigenschaften. Die Punkte der Strecke aI (eigentlich gesättigte $\mathrm{CuSO}_{4}$-Lösungen mit wenig Albumin) stellen Lösungen dar, die, wenn sie verdünnt werden, keinen Niederschlag veranlassen; in der Tat ersieht man aus der Figur, daß in diesem Falle die Punkte der Kurve nach oben verschoben würden und daß sie deshalb in das monophasische Feld eintreten würden.

Die Punkte der Strecke $\alpha \mathrm{N}^{\prime}$ (eigentlich gesättigte $\mathrm{CuSO}_{4}$ Lösungen, die reich an Albumin sind) stellen dagegen Lösungen dar, die durch Hinzufügung von $\mathrm{H}_{2} \mathrm{O}$ oder einer Albuminlösung einen Niederschlag ergeben, da alsdann wirklich die Punkte der Kurve sich nach oben und nach links verschieben, d. $h$. in das zweiphasische Feld eintreten.

Die Ergebnisse der Analyse dieser Systeme finden sich in der vorstehenden Tabelle.

Fassen wir das zusammen, was auseinandergesetzt wurde, so sieht man, daß die beiden in Fig. 6 gezeichneten Äste der Isotherme den Flächeninhalt des Dreiecks in drei Felder teilen.

Das erste, das monophasische, hat zur Einfassung die Punkte $A^{\prime}, B^{\prime}, G^{\prime}, \alpha, I, H_{2} O$; diese Einfassung ist nur links unterbrochen, weil der Punkt fehlt, in welchem die Kurve mit der (Al, $\mathrm{H}_{2} \mathrm{O}$-Achse zusammentrifft. Jeder beliebige Punkt in diesem Felde stellt eine Lösung von Serumalbumin und $\mathrm{CuSO}_{4}$ dar, die homogen und beständig ist.

Das zweite Feld, ein zweiphasisches, wird oben begrenzt durch die Kurve $\mathrm{A}^{\prime} \alpha$, links durch einen Teil der $\left(\mathrm{Al}, \mathrm{H}_{2} \mathrm{O}\right)$-Achse, unten durch einen Teil der (Al, $\mathrm{Cu}$ )-Achse (und auf dieser Strecke befinden sich die Punkte, welche mit denjenigen konjugiert sind, die die Kurve $\mathrm{A}^{\prime} \alpha$ bilden), rechts durch die Kurve $\alpha \mathrm{M}^{\prime}$. Unbestimmt bleibt die Grenze unter dem Punkt $\mathrm{M}^{\prime}$; aber es ist nicht unwahrscheinlich, daß die Kurve $\alpha \mathrm{M}^{\prime}$ sich fortsetzen muß, bis sie die (Al, $\mathrm{Cu}$ )-Achse trifft und selbst diese Grenze darstellt. Jeder Punkt dieses Feldes stellt einen Komplex dar, der sich in zwei Phasen spaltet, nämlich in eine Lösung von der Zusammensetzung $A^{\prime} \ldots \ldots G^{\prime}$ und in einen Niederschlag von der Zusammensetzung $A^{\prime \prime} \ldots G^{\prime \prime}$, und die Zusammensetzung der beiden Phasen wird durch die Konjugationsgerade bestimmt, welche durch den Punkt selbst hindurchgeht. 


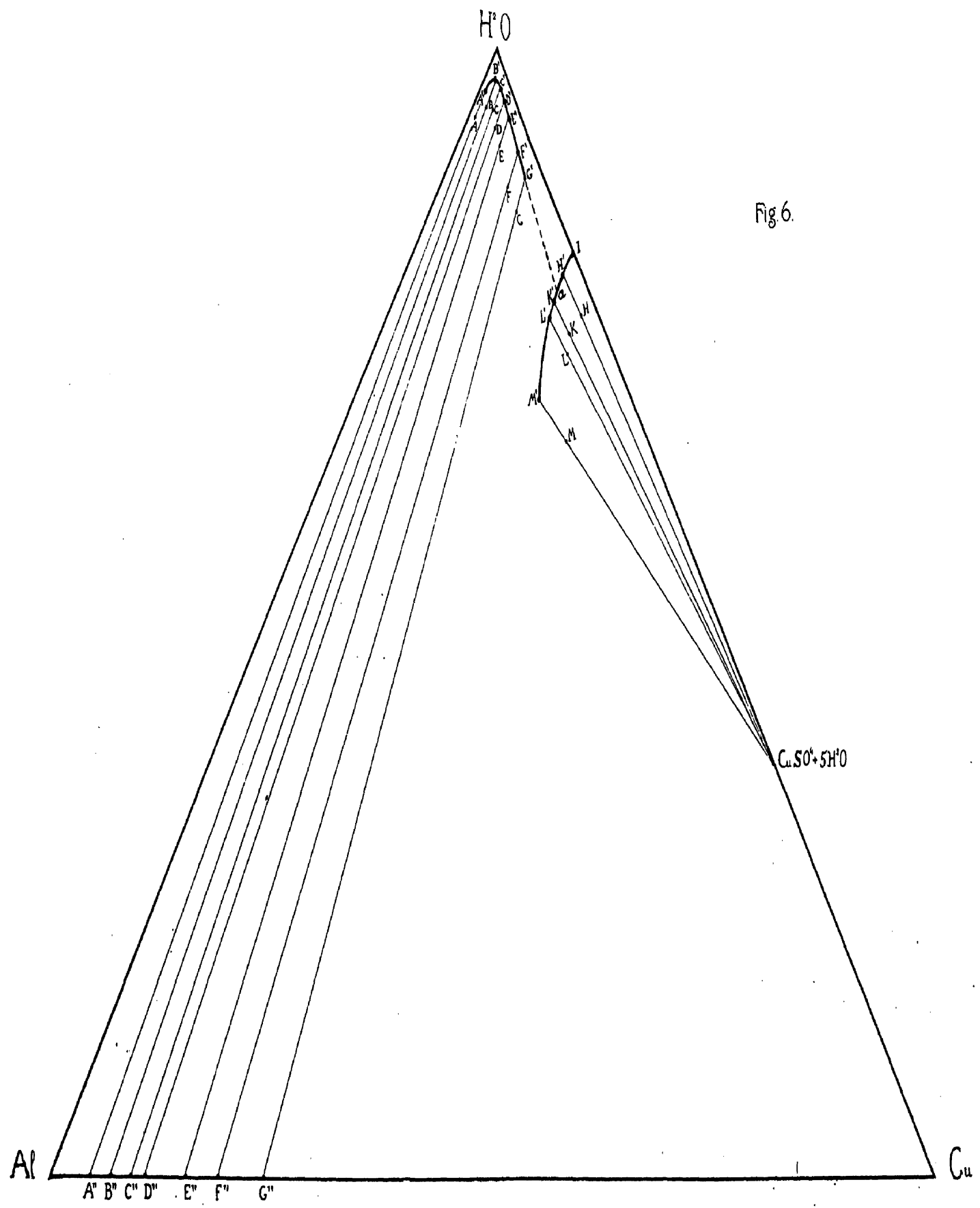

Hoppe-Seyler's Zeitschriit für physiologische Chemie. Band XL, Tafol 12.
Zn «Ga a eotti, Uber dio sogenannton Metallverbindungen der EiweiBkörper elc."

Vorlag von Karl J. Trubuer in Strabburg. 
Das dritte Feld, ebenfalls ein zweiphasisches, wird oben begrenzt durch die Kurve $M / I$, rechts durch die Strecke $\mathrm{CuSO}_{4}+5 \mathrm{H}_{2} \mathrm{O}$, I und unten würde es begrenzt durch die Gerade, welche den Punkt $\mathrm{CuSO}_{4}+5 \mathrm{H}_{2} \mathrm{O}$ mit dem Endpunkte der Kurve IM $^{\prime}$ verbindel; aber, wie schon bemerkt, dieser Punkt und folglich auch diese Grenze sind unbekannt.

Wie bei dem beim I. Versuch betrachteten System bleibt ein Teil des Dreiecks gegen den Scheitelpunkt $\mathrm{Cu}$ hin unbestimmt. Die Punkte dieses Teils würden Systemen entsprechen, die sehr arm an Wasser wären und zersetzbar in sehr konzentrierten Lösungen und in Hydrate, die niedriger wären als das Pentahydrat.

III. und IV. Versuch

System: Serumalbumin $+\mathrm{AgNO}_{3}+\mathrm{H}_{2} \mathrm{O}$

Von verschiedenen Experimenten, die ich anstellte, um

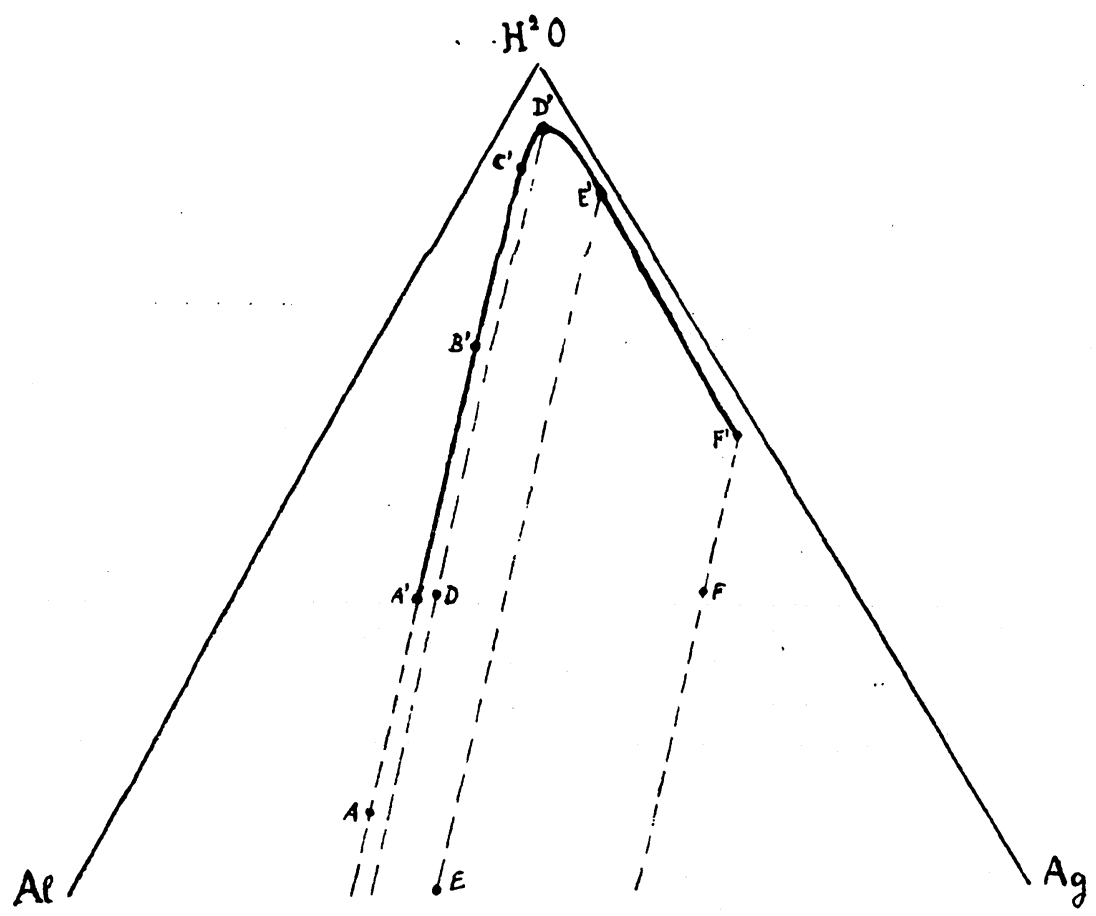

Fig. 7. 
die Gleichgewichtsbedingungen dieses Systems bei einer Temperatur von $14^{\circ}-16^{\circ} \mathrm{zu}$ bestimmen, halte ich es für angezeigt, nur über zwei zu berichten, die in den folgenden Tabellen wiedergegeben und durch die Fig. 7 und 8 dargestellt sind. Die Übereinstimmung zwischen den beiden Versuchen ist eine ziemlich befriedigende (wie aus den Figuren selbst ersichtlich), obschon die Versuche mit zwei verschiedenen Präparaten von Serumalbumin angestellt worden sind. Zuerst will ich den III. Versuch in Erwägung ziehen, weil er ausführlicher ist als der andere. Die Kurve, welche die im Gleichgewicht mit den festen Phasen (Silberalbuminate) stehenden Lösungen darstellt, ist etwas kurz, weil es mir nicht möglich war, tiefer als

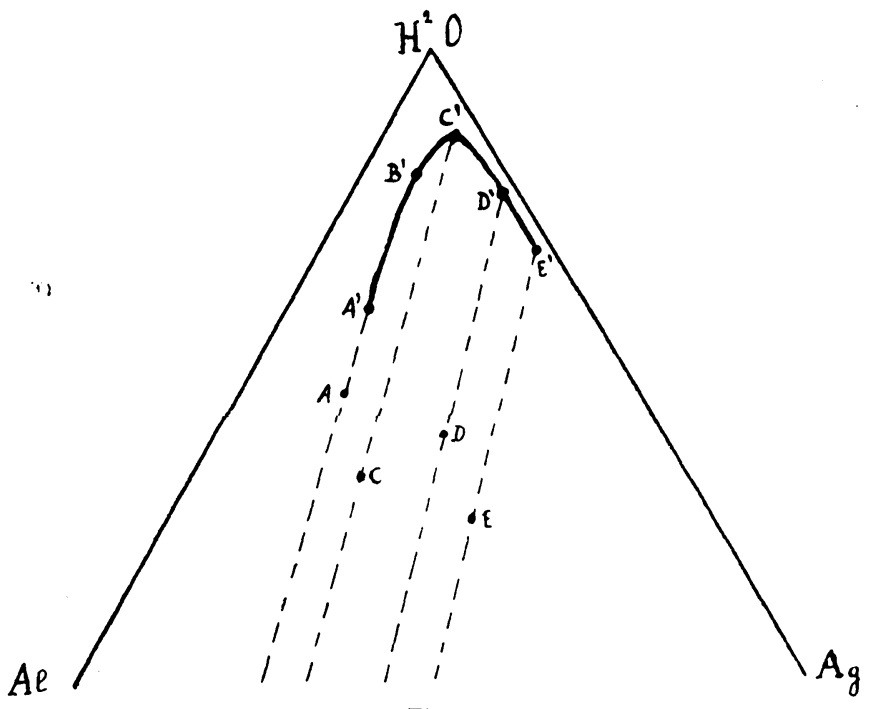

Fig. 8.

$\mathrm{A}^{\prime}$ und $\mathrm{F}^{\prime}$ (Fig. 7) gelegene Punkte zu bestimmen, insofern als Lösungen, die konzentrierter sind als $A^{\prime}$, sich absolut nicht filtrieren lassen ${ }^{1}$ ), und Lösungen, die reicher an $\mathrm{AgNO}_{3}$ sind, mir bei der Analyse große Schwierigkeiten entgegenstellten.

1) Diese Lösung $A^{\prime}$ ist gleichfalls mit sehr großer Schwierigkeit filtriert worden und, obgleich sie dem Zentrifugieren unterworfen wurde, nie vollkommen klar geworden, sondern hat ein milchiges Aussehen beibehalten. 
Was den weiteren Verlauf der Kurve nach rechts hin betrifft, so kann man natürlich denken, sie werde die $\left(\mathrm{Ag}, \mathrm{H}_{2} \mathrm{O}\right)$ Achse in dem Punkte treffen, welcher die Löslichkeit des $\mathrm{AgNO}_{3}$ darstellt; aber man kann hinsichtlich ihres Verlaufs nach links hin keine Vermutung aufstellen.

Die Kurve ist sehr regelmäßig: sie steigt fast geradlinig von $\mathrm{A}^{\prime}$ bis $\mathrm{D}^{\prime}$ (Fig. 7), wo sie einen Scheitelpunkt hat, und sinkt hierauf ebenfalls fast geradlinig von $\mathrm{E}^{\prime}$ bis $\mathrm{F}^{\prime}$, indem sie sich sehr nahe an der $\left(\mathrm{Ag}, \mathrm{H}_{2} \mathrm{O}\right)$-Achse hält.

Sie bezeichnet, wenn auch in unvollständiger Weise, die Grenze von zwei Feldern: das eine ist ein monophasisches und befindet sich im oberen Teil des Dreiecks; das andere ist ein $\mathrm{zw}$ eiphasisches und befindet sich im untern Teil desselben.

Die Breite der monophasischen Zone, die von dem Aste $\mathrm{A}^{\prime} \mathrm{D}^{\prime}$ und der $\left(\mathrm{Al}, \mathrm{H}_{2} \mathrm{O}\right)$-Achse eingeschlossen ist, zeigt, wie auch die Richtung dieses Astes, wie Lösungen, die sehr reich an Albumin sind, beträchtliche Mengen von $\mathrm{AgNO}_{3}$ enthalten können, ohne einen Niederschlag zu ergeben, wie ich es tatsächlich in meinen einleitenden Untersuchungen (S. 502) konstatieren kunnte. Ein durch einen Punkt rechts von $\mathrm{A}^{\prime} \mathrm{D}^{\prime}$ dargestelltes und deshalb zweiphasisches System kann ein monophasisches werden, d. h. sein Niederschlag kann sich wieder auflösen, wenn man Albumin in genügender Menge hinzufügt, um den Punkt selbst links von $\mathrm{A}^{\prime} \mathrm{D}^{\prime} \mathrm{zu}$ verschieben.

Die andere monophasische Zone rechts von $\mathrm{D}^{\prime} \mathrm{F}^{\prime}$ ist dagegen, wie ich schon andeutete, sehr schmal, und der Ast $\mathrm{D}^{\prime} \mathrm{F}^{\prime}$ verläuft fast parallel mit der rechten Seite des Dreiecks, was beweist, daß die Menge von Albumin, welche in einer genügend konzentrierten $\mathrm{AgNO}_{3}$-Lösung aufgelöst bleiben kann, stets gering ist, und daß diese Menge sich sehr wenig durch Steigerung der Konzentration dieses Salzes ändert. Deshalb begreift man auch, daß die Wiederauflösung eines Silberalbuminats durch Hinzufügung einer $\mathrm{AgNO}_{3}$-Lösung nur in kleinem Maß erfolgen und schwer beobachtet werden kann. Die Punkte, welche sich im zweiphasischen Felde befinden, stellen Komplexe dar, die sich sogleich spalten in eine feste Phase (Niederschlag von Albumin und $\mathrm{Ag}$ ), die durch einen 
Tabelle III (der

System: Serum-

\begin{tabular}{|c|c|c|c|c|c|c|c|c|c|}
\hline \multicolumn{10}{|c|}{ Ergebnisse der Analyse } \\
\hline \multicolumn{4}{|c|}{ Komplexe } & \multicolumn{2}{|c|}{$\begin{array}{l}\text { I. Phase - } \\
\text { Niederschlag }\end{array}$} & \multicolumn{4}{|c|}{ II. Phase - Lösungen } \\
\hline $\begin{array}{c}\text { Die } \\
\text { Komplexe } \\
\text { dar- } \\
\text { stellende } \\
\text { Punkte }\end{array}$ & $\begin{array}{c}\text { Albu- } \\
\text { min }\end{array}$ & $\mathrm{AgNO}_{3}$ & $\mathrm{H}_{2} \mathrm{O}$ & $\begin{array}{l}\text { Albu- } \\
\min \end{array}$ & $\mathrm{AgNO}_{3}$ & $\begin{array}{c}\text { Die } \\
\text { Phasen } \\
\text { dar- } \\
\text { stellende } \\
\text { Punkte }\end{array}$ & $\begin{array}{l}\text { Albu- } \\
\min \end{array}$ & $\mathrm{AgNO}_{3}$ & $\mathrm{H}_{4} \mathrm{O}$ \\
\hline A & 1,2314 & 0,4735 & 18,2588 & 0,3828 & 0,1269 & $A^{\prime}$ & 0,8486 & 0,3466 & 18,20̄88 \\
\hline - & - & - & - & - & - & $\mathrm{B}^{\prime}$ & 0,4144 & 0,1711 & 17,433 \\
\hline C & 0,4283 & 0,1719 & 29,867 & 0,1960 & $0,06 \dot{9} 9$ & $\mathrm{C}^{\prime}$ & 0,2323 & 0,1060 & 29,867 \\
\hline D & 0,5140 & 0,2049 & 11,1320 & 0,4860 & 0,1635 & $D^{\prime}$ & 0,0280 & 0,0414 & 11,1320 \\
\hline E & 1,2406 & 0,6737 & 18,1116 & 1,2211 & $0,429 \check{\jmath}$ & $\mathrm{E}^{\prime}$ & 0,0195 & 0,2442 & 18,1116 \\
\hline $\mathrm{F}$ & 0,4014 & 1,2363 & 25,4402 & 0,3530 & 0,1493 & $\mathrm{~F}^{\prime}$ & 0,0484 & 1,0870 & 25,4402 \\
\hline
\end{tabular}

Tabelle IV (der

System: Serum.

Ergebnisse der Analyse

\begin{tabular}{|c|c|c|c|c|c|c|c|c|c|}
\hline \multicolumn{4}{|c|}{ Komplexe } & \multicolumn{2}{|c|}{$\begin{array}{l}\text { I. Phase - } \\
\text { Niederschlag }\end{array}$} & \multicolumn{4}{|c|}{ II. Phase - Lösung } \\
\hline $\begin{array}{c}\text { Die } \\
\text { Komplexe } \\
\text { dar- } \\
\text { stellende } \\
\text { Punkte }\end{array}$ & $\begin{array}{c}\text { Albu- } \\
\text { min }\end{array}$ & $\mathrm{AgNO}_{3}$ & $\mathrm{H}_{2} \mathrm{O}$ & $\begin{array}{c}\text { Albu- } \\
\text { min }\end{array}$ & $\mathrm{AgNO}_{3}$ & \begin{tabular}{|c} 
Die \\
Phasen \\
dar- \\
stellende \\
Punkte
\end{tabular} & $\begin{array}{c}\text { Albu- } \\
\text { min }\end{array}$ & $\mathrm{AgNO}_{3}$ & $\mathrm{H}_{8} \mathrm{O}$ \\
\hline A & 0,7535 & 0,2748 & 24,65 & 0,1889 & 0,0621 & $\mathrm{~A}^{\prime}$ & 0,5646 & 0,2127 & 24,65 \\
\hline - & - & - & - & 0,2314 & 0,0759 & $\mathrm{~B}^{\prime}$ & 0,2351 & 0,1307 & 24,86 \\
\hline C & 0,8218 & 0,4447 & 24,88 & 0,7590 & 0,2426 & $\mathrm{C}^{\prime}$ & 0,0628 & 0,2021 & 24,88 \\
\hline D & 0,5880 & 0,5766 & 24,85 & 0,5651 & 0,2087 & $D^{\prime}$ & 0,0229 & 0,3679 & 24,85 \\
\hline & 0,6559 & 0,8002 & 24,78 & 0,6290 & 0,2509 & $\mathrm{E}^{\prime}$ & 0,0269 & 0,5493 & 24,78 \\
\hline
\end{tabular}


Über d. sog. Metallverbindungen d. Eiweißkörper nach d. Theorie etc. 539 fig. 7 entsprèchend).

bumin $+\mathrm{AgNO}_{3}+\mathrm{H}_{2} \mathrm{O}$.

Zentesimentale Zusammensetzungen der Phasen

\begin{tabular}{|c|c|c|c|c|c|c|c|c|c|}
\hline \multicolumn{4}{|c|}{ Komplexe } & \multicolumn{2}{|c|}{$\begin{array}{l}\text { I. Phase - } \\
\text { Niederschlag }\end{array}$} & \multicolumn{4}{|c|}{ II. Phase - Lösung } \\
\hline $\begin{array}{l}\text { Die } \\
\text { Siomplex } \\
\text { dar- } \\
\text { stellende } \\
\text { Punkte }\end{array}$ & $\begin{array}{c}\text { Albu- } \\
\min \end{array}$ & $\mathrm{AgNO}_{3}$ & $\mathrm{H}_{2} \mathrm{O}$ & $\begin{array}{l}\text { Albu- } \\
\min \end{array}$ & $\mathrm{AgNO}_{3}$ & $\begin{array}{c}\text { Die } \\
\text { Phasen } \\
\text { dar- } \\
\text { stellende } \\
\text { Punkte }\end{array}$ & $\begin{array}{l}\text { Albu- } \\
\min \end{array}$ & $\mathrm{AgNO}_{3}$ & $\mathrm{H}_{2} \mathrm{O}$ \\
\hline A & 6,16 & 2,37 & 91,46 & 75,10 & 24,89 & $\mathrm{~A}^{\prime}$ & 4,36 & 1,78 & 93,87 \\
\hline - & - & - & - & - & - & $\mathrm{B}^{\prime}$ & 2,30 & 0,94 & 96,75 \\
\hline C & 1,40 & 0,56 & 98,03 & 74,84 & 25,16 & $\mathrm{C}^{\prime}$ & 0,77 & 0,35 & 98,88 \\
\hline D & 4,33 & 1,73 & 93,93 & 74,80 & 25,20 & $\mathrm{D}^{\prime}$ & 0,25 & 0,37 & 99,38 \\
\hline $\mathrm{E}$ & 6,19 & 3,36 & 90,44 & 73,98 & 26,02 & $E^{\prime}$ & 0,10 & 1,33 & 98,56 \\
\hline $\mathrm{F}$ & 1,48 & 4,56 & 93,95 & 70,28 & 29,73 & $F^{\prime}$ & 0,18 & 4,09 & 95,73 \\
\hline
\end{tabular}

iig. 8 entsprechend).

thumin $+\mathrm{AgNO}_{3}+\mathrm{H}_{2} \mathrm{O}$.

Zentesimentale Zusamensetzungen der Phasen

\begin{tabular}{|c|c|c|c|c|c|c|c|c|c|}
\hline \multicolumn{4}{|c|}{ Komplexe } & \multicolumn{2}{|c|}{$\begin{array}{l}\text { I. Phase - } \\
\text { Niederschlag }\end{array}$} & \multicolumn{4}{|c|}{ II. Phase - Lösung } \\
\hline $\begin{array}{l}\text { Die } \\
\text { iomplexe } \\
\text { dar- } \\
\text { tellende } \\
\text { Punkte }\end{array}$ & $\begin{array}{c}\text { Albu- } \\
\min \end{array}$ & $\mathrm{AgNO}_{3}$ & $\mathrm{H}_{8} \mathrm{O}$ & $\begin{array}{l}\text { Albu- } \\
\min \end{array}$ & $\mathrm{AgNO}_{3}$ & $\begin{array}{c}\text { Die } \\
\text { Phasen } \\
\text { dar- } \\
\text { stellende } \\
\text { Punkte }\end{array}$ & $\begin{array}{c}\text { Albu- } \\
\min \end{array}$ & $\mathrm{AgNO}_{3}$ & $\mathrm{H}_{2} \mathrm{O}$ \\
\hline A & 2,93 & 1,07 & 95,99 & 75,26 & 24,74 & $A^{\prime}$ & 2,22 & 0,84 & 96,94 \\
\hline- & - & - & - & 75,30 & 24,70 & $\mathrm{~B}^{\prime}$ & 0,93 & 0,52 & 98,54 \\
\hline C & 3,14 & 1,70 & 95,15 & 75,78 & 24,22 & $C^{\prime}$ & 0,25 & 0,80 & 98,94 \\
\hline D & 2,21 & 2,26 & 95,53 & 73,03 & 26,97 & $\mathrm{D}^{\prime}$ & 0,09 & 1,45 & 98,45 \\
\hline B & 2,50 & $3,0 \check{\jmath}$ & 94,45 & 71,49 & 28,51 & $\mathrm{E}^{\prime}$ & 0,10 & 2,16 & 97,73 \\
\hline
\end{tabular}


Punkt der (Al, Ag)-Achse dargestellt wird, und in eine einem Punkt der Isotherme $\mathrm{A}^{\prime} \mathrm{F}^{\prime}$ entsprechende Lösung.

In den Fig. 7 und 8 habe ich nur einen Teil des gewöhnlichen gleichseitigen Dreiecks gezeichnet, weil ich, um eine deutliche Reproduktion der Isothermen zu erhalten, bei den Seiten des Dreiecks die Länge von 1 Meter beibehalten mußte. Die (Al, Ag)-Achse kann also in der oben erwähnten Figur nicht gefunden werden; aber die Gleichgewichtsbedingungen zwischen den festen und flüssigen Phasen sind bestimmt durch die Richtung der Konjugationsgeraden, die gezeichnet worden sind. Auf diesen befinden sich die den analysierten Komplexen entsprechenden Punkte (A, B, C, D, E, F). Man sieht sogleich, daß die Konjugationsgeraden parallel verlaufen, oder leicht von einander abweichen und insbesondere, daß sie nicht danach streben, sich zu treffen; dies bedeutet, daß das Gleichgewicht sich eindeutig bestimmt ergibt, wenigstens für alle Komplexe, die durch Punkte dargestellt sind, welche sich in der von diesen Konjugationsgeraden durchschnittenen Zone befinden. Ferner sieht man, daß Lösungen, in welchen das Silbersalz in geringerer Konzentration vorhanden ist, im Gleichgewicht sind mit Niederschlägen, die ärmer an $\mathrm{Ag}$ sind und umgekehrt.

Die analytischen Ergebnisse dieser Experimente findet man in den vorstehenden Tabellen (Tab. III u. IV).

Vergleichen wir diese Resultate mit den im vorhergehenden erhaltenen hinsichtlich des $\mathrm{CuSO}_{4}$, so können gleichzeitig mit einer allgemeinen Ähnlichkeit des Verhaltens einige Unterschiede hervorgehoben werden, von denen es mich nur interessiert, auf die folgenden hinzuweisen.

Der Teil des monophasischen Feldes, welcher sich links von dem ansteigenden Aste der verschiedenen Isothermen befindet, ist eine breite Zone für den Fall des $\mathrm{AgNO}_{3}$, während er ein feiner Streifen für den Fall des $\mathrm{CuSO}_{4}$ ist. Dies zeigt uns, daß sehr konzentrierte Albuminlösungen, indem sie dennoch homogen bleiben, beträchtliche Mengen von $\mathrm{AgNO}_{3}$ enthalten können, während sie sich durch Hinzufügung kleiner Mengen von $\mathrm{CuSO}_{4}$ niederschlagen und daß durch Hinzufügung von Albumin ein Silberalbuminat sich reichlich wieder auflöst, 
Über d. sog. Metallverbindungen d. Eiweißkörper nach d. Theorie etc. 541

während ein Kupferalbuminat sich in viel geringerem Maß wieder auflöst.

Dagegen ist der Teil des monophasischen Feldes, welcher sich rechts von dem absteigenden Zweig der Isothermen befindet, ein feiner Streifen bezüglich der Systeme mit $\mathrm{AgNO}_{3}$ und eine ziemlich breite Zone bezüglich der Systeme mit $\mathrm{CuSO}_{4}$. Dies beweist, daß sehr konzentrierte Salzlösungen viel Albumin enthalten können, wenn das $\mathrm{Salz} \mathrm{CuSO}_{4}$ ist, während sie nur sehr wenig davon enthalten können, wenn das Salz $\mathrm{AgNO}_{3}$ ist. Übrigens kann man auch hier wahrnehmen, daß der Niederschlag, welcher sich schon gebildet hatte, sich leicht und reichlich wieder auflöst in einer konzentrierten Lösung von $\mathrm{CuSO}_{4}$, während dies in sehr kleinem $\mathrm{Maß}$ bei den Lösungen mit $\mathrm{AgNO}_{3}$ geschieht.

\section{Versuch.}

System: Kristallisiertes Eieralbumin $+\mathrm{AgNO}_{3}+\mathrm{H}_{2} \mathrm{O}$.

Kristallisiertes Albumin stellte ich nach der Methode Hopkins und Pinkus dar; nach einer mehrtägigen Dialyse in fließendem destillierten Wasser erhielt ich es mit einer sehr kleinen Menge Asche $(0,25 \%)$. Wegen der kleinen Menge des Präparats, die ich erhalten hatte, konnte ich aber nur ein unvollständiges Experiment ausfübren, das mir jedoch zur Kontrolle gedient hat.

Bei diesem Experiment habe ich die Mischungen mit genau bestimmten Mengen von Lösungen von Albumin und $\mathrm{AgNO}_{3}$ ausgeführt, die sorgfältig titriert waren; dann habe ich die nach der Titrierung der Lösungen berechneten Mengen dieser Substanzen in den Komplexen mit den Mengen verglichen, die sich mir aus der Analyse der beiden Phasen (Lösungen und Niederschläge) ergaben. Die bei der Analyse und bei der Richtigstellung der erhaltenen Zahlen befolgte Methode war die nämliche, welche ich oben (Seite $515-516$ ) beschrieben habe.

In der folgenden Tabelle finden sich alle diese Angaben, und man kann sehen, daß die bei der Analyse aufgefundenen Mengen der beiden Phasen so ziemlich mit den für die Mischungen berechneten Mengen übereinstimmen.

Hoppe-Seyler's Zeitschrift f. physiol. Chemie. XL. 
Aus dieser Tabelle ersieht man außerdem, daß die $\mathrm{Zu}-$ sammensetzung des Silberalbuminats variiert, und zwar in demselben Sinne mit der Zusammensetzung der Lösung, mit welcher es sich im Gleichgewicht befindet. Auch ist zu bemerken, daß die von dem Eieralbumin gebundenen Ag-Mengen kleiner sind als diejenigen, welche das Serumalbumin imstande ist, unter gleichen Bedingungen $\mathrm{zu}$ binden.

Tabelle V.

\begin{tabular}{|c|c|c|c|c|c|c|c|c|c|c|}
\hline & \multicolumn{5}{|c|}{ Ergebnisse der Analysen } & \multicolumn{5}{|c|}{$\begin{array}{c}\text { Zentesimale Zusammensetzung } \\
\text { der Phasen }\end{array}$} \\
\hline & \multicolumn{2}{|c|}{ Feste Phase } & \multicolumn{3}{|c|}{ Flüssige Phase } & \multicolumn{2}{|c|}{ Feste Phase } & \multicolumn{3}{|c|}{ Flüssige Phase } \\
\hline & $\underset{\mathrm{min}}{\mathrm{Albu}-}$ & $\mathrm{AgNO}_{8}$ & $\underset{\min }{\operatorname{Albu}-}$ & $\mathrm{AgNO}_{3}$ & $\mathrm{H}_{2} \mathrm{O}$ & $\underset{\mathrm{min}}{\text { Albu- }}$ & $\mathrm{AgNO}_{3}$ & $\begin{array}{c}\text { Albu- } \\
\text { min }\end{array}$ & $\mathrm{AgNO}_{3}$ & $\mathrm{H}_{2} \mathrm{O}$ \\
\hline A & 0,3720 & 0,0542 & 0,0595 & 0,1846 & 43,377 & 87,28 & 12,72 & 0,14 & 0,42 & 99,44 \\
\hline B & 0,2584 & 0,0394 & 0,0487 & 0,2644 & 39,565 & 86,77 & 13,23 & 0,12 & 0,66 & 99,21 \\
\hline $\mathrm{C}$ & 0,1792 & 0,0356 & 0,0176 & 0,4033 & 39,322 & 83,43 & 16,57 & 0,04 & 1,01 & 98,94 \\
\hline D & 0,0714 & 0,0195 & 0,0128 & 0,5547 & 39,711 & 78,55 & 21,45 & 0,03 & 1,37 & 98,59 \\
\hline
\end{tabular}

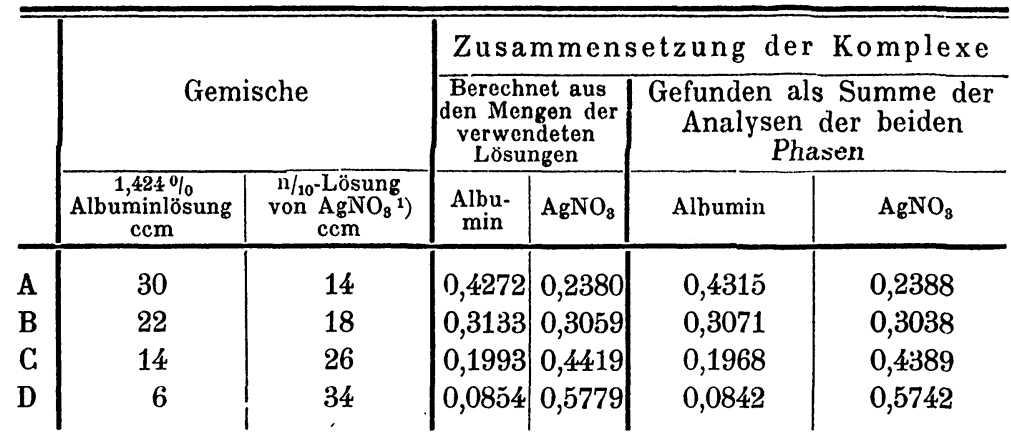

VI. Versuch. Labile Lösungen.

Die Erfahrung hat mir bewiesen, daß bei den jetzt von mir untersuchten Systemen auch labile Lösungen vorhanden sind, d. h. Lösungen, welche eine gewisse Zeit lang homogen bleiben und dann sich entweder spontan oder infolge einer geeigneten Ursache spalten in eine stabile Lösung und in eine

1) Bei dieser Lösung wurde gefunden, als sie kontrolliert war, daß sie genau 1,699\% $\mathrm{AgNO}_{3}$ enthielt. 
Über d. sog. Metallverbindungen d. Eiweißkörper nach d. Theorie etc. 543

feste Phase; es ist mir gelungen (zugleich mit den stabilen Isothermen), andere Kurvenäste zu bestimmen, welche die Felder begrenzen, auf denen sich die diese labilen Phasen darstellenden Punkte befinden.

Solchen labilen Kurven entsprechen gewisse Krümmungen der Potentialfläche, und deshalb hat die Kenntnis derselben eine gewisse Bedeutung für den Entwurf der Potentialfläche selbst; ich kann aber hier nicht allzu weitschweifig diese Frage in Untersuchung ziehen, welche bezüglich gewisser spezieller Fälle eingehend von Schreinemakers behandelt worden ist.

In dieser Hinsicht habe ich nur das System: Eieralbumin $+\mathrm{CuSO}_{4}+\mathrm{H}_{2} \mathrm{O}$ untersucht und zwei Äste labiler Kurven bestimmen können, welche durch punktierte Linien dargestellt werden, die

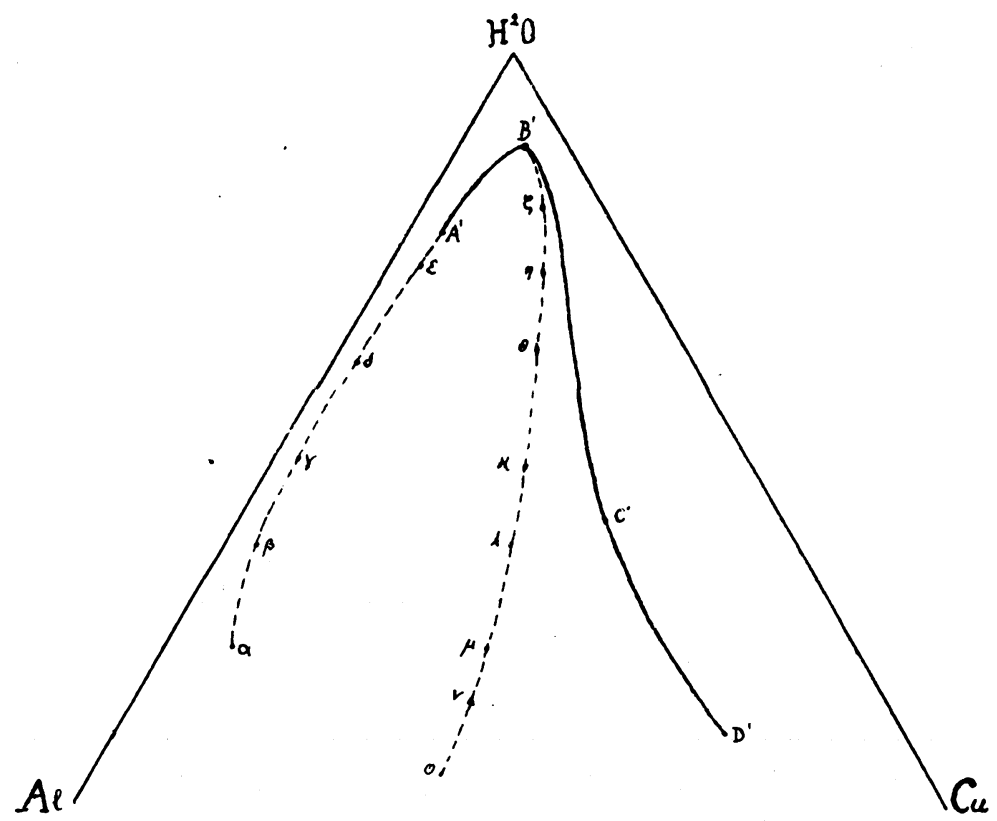

Fig. 9.

in Fig. 9 gezogen sind; in dieser findet sich auch die stabile Isotherme, welche dem I. Versuch entnommen wurde.

Zur Bestimmung dieser Kurve habe ich eine synthetische Methode angewendet, die ich jetzt erklären will, indem ich 
berichte, auf welche Weise ich den labilen Kurvenast $\mathrm{oB}^{\prime}$ konstruiert habe. Ich stellte eine Reihe von kleinen Gläsern (6-10) zurecht und schüttete in jedes von ihnen $2 \mathrm{ccm}$ einer $\mathrm{CuSO}_{4^{-}}$ Lösung, die ich mit der größten Sorgfalt titriert hatte. Dann goß ich in jedes Glas eine Lösung von Eieralbumin, die ebenfalls gut titriert worden war, sodaß jedes Glas ungefähr $2 / 10 \mathrm{ccm}$ mehr enthielt, als das vorhergehende.

Hier muß ich daran erinnern, daß eine Albuminlösung in wachsenden Mengen einer konstanten Menge von $\mathrm{CuSO}_{4-}^{-}$ Lösung hinzufügen, in unserer graphischen Darstellung der Verschiebung eines zuerst auf der $\left(\mathrm{H}_{2} \mathrm{O}, \mathrm{Cu}\right)$-Achse gelegenen Punktes nach links und oben entspricht.

Die Gläser mit den oben erwähnten Mischungen wurden dann geschüttelt und 4-6 Stunden lang beobachtet, und so konnte ich wiederholt konstatieren, daß die eine geringere Menge Albumin enthaltenden Lösungen immerwährend klar und homogen blieben; diese entsprachen den Punkten des monophasischen Feldes $\mathrm{D}^{\prime}, \mathrm{Cu}, \mathrm{H}_{2} \mathrm{O}, \mathrm{B}^{\prime}$. Sodann blieben in einigen Gläsern die Lösungen eine Zeitlang klar, und wenn diese Zeit verflossen war, begann sich ein Niederschlag zu bilden, der allmählich zunahm, bis die Mischung sich in die beiden gewöhnlichen Phasen spaltete. Diese Lösungen gehören zum Felde $\mathrm{D}^{\prime}, \mathrm{B}^{\prime}$, o, welches gerade das labile Feld ist, das ich suchte. Wenn das Gleichgewicht eintritt, so machen diese Systeme stabilen Lösungen Platz, die sich auf der Isotherme $\mathrm{D}^{\prime}, \mathrm{B}^{\prime}$ befinden, sowie festen Phasen, die sich in der (Al, $\mathrm{Cu})$-Achse befinden.

Endlich bildet sich in anderen Gläsern mit einer größeren Menge Albumin sofort ein leichter Niederschlag, der dann mit der Zeit immer mehr zunimmt. Diese Mischungen gehören zu dem Felde links von der Kurve $\mathrm{oB}^{\prime}$. Das erste Glas unter diesen, d. h. die Mischung, welche, da sie eine kleinere Menge Albumin enthält, sofort einen leichten Niederschlag zeigt, entspricht einem Punkte der Kurve oB'

Um diesen Punkt $z u$ bestimmen, bleibt dann nichts anderes übrig, als die Zusammensetzung dieser Mischungen kennen zu lernen; zu diesem Zwecke bediente ich mich aber nicht der gewöhnlichen Analysen, sondern begnügte mich damit, die Kon- 
zentrationen des Albumins und des $\mathrm{CuSO}_{4}$ kennen zu lernen, indem ich auf die Menge und Titrierung der Lösungen achtete, aus welchen sich die Mischung selbst ergab. Es ist klar, daß man bei Anwendung dieser Methode einen Fehler begeht, der darin besteht, daß man annimmt, die Mengen Albumin und $\mathrm{CuSO}_{4}$, welche den Niederschlag bilden, gehörten der Lösung an; aber wenn dieser Niederschlag sehr spärlich ist, so ist auch der Fehler sehr klein.

Das soeben beschriebene Verfahren wurde dann mit konzentrierteren Lösungen von $\mathrm{CuSO}_{4}$ und Albumin wiederholt, und so gelang es mir, andere Punkte der Kurve $\mathrm{oB}^{\prime}$ zu bestimmen, wie sie in Fig. 9 angegeben sind.

Diese labile Kurve o $\mathrm{B}^{\prime}$ fällt wahrscheinlich auf einer kleinen Strecke zusammen mit der stabilen Isotherme $B^{\prime} D^{\prime}$, insofern als der nach der analytischen Methode der stabilen Lösungen bestimmte Punkt $B^{\prime}$ sich mir auch bei Anwendung der oben geschilderten synthetischen Methode ergab. Dann trennt sich die labile Kurve von der stabilen, steigt abwärts nach unten und wendet sich mit leichter Konkavität nach links.

Hieraus ersieht man, daß die verdünnten Lösungen von Albumin und $\mathrm{CuSO}_{4}$ nie labil sind, oder mit anderen Worten, daß in ihnen sofort das Gleichgewicht definitiv eintritt. Die labilen Lösungen beginnen zu erscheinen, wenn der Wassergehalt abnimmt, und die Wahrscheinlichkeiten ihres Vorhandenseins bei verschiedenen Konzentrationen vergrößern sich, je weniger Wasser die Komplexe enthalten. In der Tat erweitert sich das Feld der labilen Lösungen, d. h. der von den beiden Kurven $\mathrm{oB}^{\prime}$ und $\mathrm{B}^{\prime} \mathrm{D}^{\prime}$ eingeschlossene Flächeninhalt, indem es nach unten abwärts steigt.

Auf ähnliche Weise, wie ich es soeben beschrieben habe, wurde die labile Kurve $\alpha \mathrm{A}^{\prime}$ konstruirt. Ich schüttete nämlich in eine Reihe von Gläsern eine bestimmte Menge einer titrierten Albuminlösung und goß dann verschiedene Mengen einer $\mathrm{CuSO}_{4}-$ Lösung hinzu. Von diesen Mischungen stellte diejenige, in welcher sich sofort etwas Niederschlag bildete, einen Punkt der Kurve dar.

Diese Kurve $\alpha \mathrm{A}^{\prime}$ hat auch von Anfang an; d. h. von $\mathrm{A}^{\prime}$ bis $r$ (siehe Fig. 9), dieselbe Richtung wie der ansteigende 
Zweig $\mathrm{A}^{\prime} \mathrm{B}^{\prime}$ der stabilen Isotherme; dann entfernt er sich etwas von $\gamma$ bis $\alpha$, indem er sich nach rechts biegt. |Von den links von dieser Kurve liegenden Punkten stellen diejenigen, welche $\operatorname{der}\left(\mathrm{Al}, \mathrm{H}_{2} \mathrm{O}\right)$-Achse am nächsten sind, stabile Lösungen dar, die der Kurve selbst am nächsten liegenden Punkte Lösungen, welche eine Zeitlang als solche bestehen und dann einem Niederschlag Platz machen. Die Punkte rechts von $\alpha A^{\prime}$ entsprechen Komplexen, die sich sofort in zwei Phasen spalten.

In der folgenden Tabelle sind die Zahlenangaben von solchen Untersuchungen aufgeführt.

Tabelle VI (der Fig. 9 entsprechend).

Labile Lösungen des Systems: Eieralbumin $+\mathrm{CuSO}_{4}+\mathrm{H}_{2} \mathrm{O}$.

\begin{tabular}{|c|c|c|c|c|c|c|c|}
\hline \multicolumn{5}{|c|}{ Menge der Komponenten } & \multicolumn{3}{|c|}{$\begin{array}{c}\text { Zentesimentale } \\
\text { Zusammensetzungen des } \\
\text { Lösungen }\end{array}$} \\
\hline & $\begin{array}{c}\text { Die Lösungen } \\
\text { darstellenden } \\
\text { Punkte }\end{array}$ & \begin{tabular}{|c|} 
Albu- \\
min
\end{tabular} & $\mathrm{CuSO}_{4}$ & $\mathrm{H}_{2} \mathrm{O}$ & $\begin{array}{c}\text { Albu- } \\
\text { min }\end{array}$ & $\mathrm{CuSO}_{4}$ & $\mathrm{H}_{2} \mathrm{O}$ \\
\hline $\begin{array}{l}\text { Rechter } \\
\text { Ast }\end{array}$ & 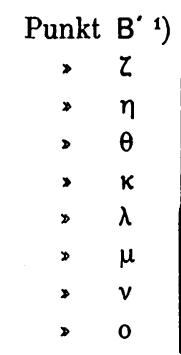 & $\begin{array}{l}0,1708 \\
0,1130 \\
0,1320 \\
0,1544 \\
0,1884 \\
0,5180 \\
0,584 \\
0,640 \\
0,698\end{array}$ & $\begin{array}{l}0,2353 \\
0,2030 \\
0,2030 \\
0,2030 \\
0,2030 \\
0,4846 \\
0,4846 \\
0,4846 \\
0,4846\end{array}$ & $\begin{array}{c}24,620 \\
12,2 \\
8,4 \\
6,6 \\
5,0 \\
10,5 \\
9,2 \\
8,8 \\
8,2\end{array}$ & $\begin{array}{l}0,68 \\
0,9 \\
1,5 \\
2,2 \\
3,4 \\
4,4 \\
5,6 \\
6,4 \\
7,4\end{array}$ & \begin{tabular}{l|}
0,94 \\
1,6 \\
2,9 \\
2,9 \\
3,7 \\
4,2 \\
4,7 \\
4,8 \\
5,1
\end{tabular} & $\begin{array}{l}98,38 \\
97,4 \\
96,2 \\
94,9 \\
92,7 \\
91,4 \\
89,6 \\
88,7 \\
87,4\end{array}$ \\
\hline $\begin{array}{l}\text { Linker } \\
\text { Ast }\end{array}$ & $\begin{array}{c}\left.\text { Punkt } A^{\prime}{ }^{\prime}\right) \\
\Rightarrow \quad \epsilon \\
=\delta \\
\Rightarrow \quad \gamma \\
\Rightarrow \quad \beta\end{array}$ & $\begin{array}{l}0,6438 \\
0,434 \\
0,448 \\
0,462 \\
0,448 \\
0,462\end{array}$ & $\left|\begin{array}{l}0,1481 \\
0,042 \\
0,027 \\
0,014 \\
0,027 \\
0,053\end{array}\right|$ & \begin{tabular}{|c|}
24,102 \\
12,6 \\
8,5 \\
6,2 \\
5,1 \\
4,4
\end{tabular} & $\begin{array}{l}2,58 \\
3,3 \\
5,0 \\
6,8 \\
8,0 \\
9,4\end{array}$ & \begin{tabular}{l|}
0,59 \\
0,3 \\
0,3 \\
0,3 \\
0,5 \\
1,0
\end{tabular} & $\begin{array}{l}92,82 \\
96,3 \\
94,7 \\
92,9 \\
91,4 \\
89,6\end{array}$ \\
\hline
\end{tabular}

Außerdem kann man andere labile Lösungen erhalten in einer Zone unterhalb der Kurve $\mathrm{H}^{\prime} \mathrm{F}^{\prime}$ in Fig. 5. Von dieser Zone konnte ich einige isolierte Punkte finden; es war mir aber unmöglich, eine Kurve zu entwerfen, welche unten dieses labile Feld abgrenzte.

1) Die Zahlen dieser Punkte sind der Tabelle I entnommen. 
Die Komplexe H, G und F (Fig. 5) sind alle durch ein Stadium hindurchgegangen, während dessen sie labile Lösungen waren. Die Mischungen, welche ich in der Tat herstellte, um diese Komplexe $\mathrm{zu}$ bilden, blieben eine gewisse Zeit lang (24-48 Stunden) vollkommen klar und ohne Kristalle; dann erfolgte entweder spontan oder durch Impfung mit einem kleinen Kristall die Kristallbildung und die Bildung des Niederschlages.

\section{Zusammenfassung.}

1. Aus den in der Literatur gefundenen Angaben sowie aus den von mir jetzt ermittelten Tatsachen kann man schließen, daß zwischen den Salzen der Schwermetalle und den Eiweißkörpern sich keine echten Verbindungen mit konstanten Beziehungen im Sinne der Valenztheorie bilden. Die in den Mischungen dieser Substanzen entstehenden Niederschläge, die sogenannten Metallalbuminate, sind als lockere Bindungen der Eiweißkörper mit den Metallen nach veränderlichen Verhältnissen anzusehen.

2. Diese Präzipitationserscheinungen sind reversibel, weil im allgemeinen die Niederschläge sich bei einem Überschuß des einen oder des anderen Bestandteiles wieder auflösen.

3. Die Zusammensetzung eines Niederschlages hängt ab von der Zusammensetzung der mit ihm in Berührung gebliebenen Lösung nach den thermodynamischen Gesetzen der chemischen Gleichgewichte.

4. Für die aus Eieralbumin oder Serumalbumin und aus $\mathrm{CuSO}_{4}$ oder $\mathrm{AgNO}_{3}$ entstehenden Systeme und für eine Temperatur zwischen $14^{\circ}$ und $16^{\circ}$ gelang es mir, das Problem des Gleichgewichtes graphisch zu lösen, d. h. die Daten anzugeben, nach welchen man, wenn die centesimale Zusammensetzung eines gegebenen Komplexes festgestellt ist, sofort bestimmen kann, in wieviel Phasen der Komplex sich abtrennen wird, und welches die Zusammensetzung jeder Phase sein wird. Diese graphischen Daten, welche durch die gezeichneten Isothermen und Konjugationsgeraden dargestellt sind, definieren also auch das Gesetz, nach welchem die Zusammensetzung eines Albuminniederschlages von derjenigen der entsprechenden Lösung abhängt. 


\section{Literatur.} Schulz).

Berzelius, Mulder, Schmidt, Danilewsky (zitiert von

1. Sjöqvist, Physiologisch-chemische Betrachtungen über Salzsäure. Skandinavisches Archiv f. Physiol., Bd. V, S. 277, 1894 u. Bd. VI, S. 225, 1895.

2. Cohnheim, Über das Salzsäurebindungsvermögen der Albumose und Peptone. Zeitschr. f. Biologie, N. F., Bd. XV, S. 489, 1896.

3. Bugarszky u. Liebermann, Über das Bindungsvermögen eiweißartiger Körper für Salzsäure. Pflügers Arch., Bd. LXXII. S. 51, 1898.

4. Spiro u. Pemsel, Über Basen- und Säurekapazität des Blutes und der Eiweißkörper. Diese Zeitschr., Bd. XXVI, S. 233, 1898.

5. Cohnheim u. Krüger, Das Verhalten der Eiweißkörper zu Alkaloidreagentien zugleich eine Bestimmung der gebundenen Salzsäure. Zeitschr. f. Biol., N. F., Bd. XXII, S. 95, 1900.

6. Bohrer, Über die Bestimmung des Säurebindungsvermögens der Eiweißstoffe. Pflügers Arch., Bd. XC: H. 7/8, 1902.

7. Schulz, Die Größe des Eiweißmoleküls. Jena, Fischer, 1903.

8. Zsigmondy, Die hochrote Goldlösung als Reagens auf Kolloide. Zeitschr. f. analyt. Chem., Bd. 40, S. 697.

9. Schulz u. Zsigmondy, Die Goldzahl und ihre Verwertbarkeit zur Charakterisicrung des Eiweißstoffes. Beiträge zur chem. Physiol u. Pathol., Bd. 3, S. 137, 1902.

10. Paal, Verschicdene Boitrïge in den chem. Ber., Bd. 35.

11. Diak on ow, Über Platinverbindungen der Eiweißkörper. Hop p eSeylers med.-chem. Untersuchungen, 1867, S. 228.

12. Fuchs, Über Äquivalentbestimmungen des Albumins. Lie bigs Annalen, Bd. 15̃1, S. 372, 1869 u. Ann. f. Chem. u. Pharm., Bd. 151, S. 372.

13. Lieberkühn, Über Albumin und Casein. Poggendorfs Annalen, Bd. 86, S. 117 u. 298, 18 2̌2.

14. Loew, Über Eiweiß und Peptone. Pflügers Arch., Bd. XXXI, S. $393,1883$.

15. Siegfried, Über Fleischsäure. Arch. f. Anat. u. Phys., Phys. Abt. 1894, S. 401.

16. Fano u. Enriques, Sui cosi detti composti salino-proteici. Atti d. R. Acc. dei Lincei, Vol. XII, p. 491, 1903.

17. Harnack, Untersuchungen über die Kupferverbindungen des Albumins. Diese Zeitschr., Bd. V, S. 198, 1881.

18. Mörner, zitiert von Schulz.

19. Chittenden $u$. Whitehouse, On the metallic combinations of Albumin and Myosin. Studies from the labor. of physiol. chemistry. Yale University, Bd. II, S. 95. 
Über d. sog. Metallverbindungen d. Eiweißkörper nach d. Theorie etc. 549

20. Brunner, Ritthausen, Ritthausen u. Pott (zitiert von S chulz).

21. Schulz, Kommt in der Sepiaschulpe Cellulose vor? Diese Zeitschr., Bd. XXIX, S. 124, 1900.

22. Rose, Neebe (zitiert von Harnack).

23. Linden u. Pich on, Journal of the Chem. Society, Bd. 67, S. 63.

24. Whitney u. Ober, Diese Zeitschr., Bd. XXXIX, S. 930, 1902.

25. Hopkins and Pinkus, Observation on the crystallisation of animal Proteids. Journal of Physiol., Bd. XXIII, S. 130, 1898-99.

26. Bakhui s-Ro oz eboom, Über die Löslichkeit von Mischkristallen, speziell zweier isomorpher Körper. Zeitschr. f. physik. Chem., Bd. VIII, S. 504, 1891.

- - Die Gleichgewichte von Lösungen zweier oder dreier Bestandteile mit festen Phasen. Zeitschr. f. physik. Chem., Bd. XII, S. 359, 1893.

27. Van Rijn van Alkemade, Graphische Behandlung einiger thermodynamischen Probleme. Zeitschr. f. physik. Chem., Bd. XI, S. 305, 1890.

28. Schreinemakers, Gleichgewicht bei Systemen von drei Komponenten, wobei zwei flüssige Phasen auftreten können. Zeitschr. f. physik. Chemie, Bd. 22, S. 93, 1897 und andere Abhandlungen in derselben Zeitschr., Bd. 23, S. 417; Bd. 25, S. 305, 543; Bd. 26, S. 237; Bd. 27, S. 95 ; Bd. 29, S. 577; Bd. 30, S. 460; Bd. 33, S. 74, 78; Bd. 41, S. 33; Bd. 35, S. 459; Bd. 39, S. 485 . 